\title{
Frequency Domain Multimodel Analysis of the Response of Atlantic Meridional Overturning Circulation to Surface Forcing
}

\author{
DOUGLAS G. MACMARTIN \\ Control and Dynamical Systems, California Institute of Technology, Pasadena, California \\ ELI TZIPERMAN \\ Earth and Planetary Sciences, and School of Engineering and Applied Sciences, Harvard University, Cambridge, Massachusetts \\ LAURE ZANNA \\ Atmospheric, Oceanic, and Planetary Physics, University of Oxford, Oxford, United Kingdom
}

(Manuscript received 30 September 2012, in final form 6 March 2013)

\begin{abstract}
The dynamics of the Atlantic meridional overturning circulation (AMOC) vary considerably among different climate models; for example, some models show clear peaks in their power spectra while others do not. To elucidate these model differences, transfer functions are used to estimate the frequency domain relationship between surface forcing fields, including sea surface temperature, salinity, and wind stress, and the resulting AMOC response. These are estimated from the outputs of the Coupled Model Intercomparison Project phase 5 (CMIP5) and phase 3 (CMIP3) control runs for eight different models, with a specific focus on Geophysical Fluid Dynamics Laboratory Climate Model, version 2.1 (GFDL CM2.1), and the Community Climate System Model, version 4 (CCSM4), which exhibit rather different spectral behavior. The transfer functions show very little agreement among models for any of the pairs of variables considered, suggesting the existence of systematic model errors and that considerable uncertainty in the simulation of AMOC in current climate models remains. However, a robust feature of the frequency domain analysis is that models with spectral peaks in their AMOC correspond to those in which AMOC variability is more strongly excited by high-latitude surface perturbations that have periods corresponding to the frequency of the spectral peaks. This explains why different models exhibit such different AMOC variability. These differences would not be evident without using a method that explicitly computes the frequency dependence rather than a priori assuming a particular functional form. Finally, transfer functions are used to evaluate two proposed physical mechanisms for model differences in AMOC variability: differences in Labrador Sea stratification and excitation by westward-propagating subsurface Rossby waves.
\end{abstract}

\section{Introduction}

The Atlantic meridional overturning circulation (AMOC) carries large amounts of heat and salt to high latitudes, therefore strongly influencing North Atlantic Ocean climate variability on a wide range of time scales. Fluctuations of the AMOC are often thought to be associated with the Atlantic decadal variability of sea surface temperatures (SST) and atmospheric surface pressure (Kushnir 1994; Enfield et al. 2001; Deser and Blackmon

Corresponding author address: D. MacMartin, California Institute of Technology, 1200 E. California Blvd., Pasadena, CA 91125.

E-mail: macmardg@cds.caltech.edu
1993; Mann and Park 1994; Sutton and Allen 1997), sea ice extent (Mahajan et al. 2011), and carbon uptake (Froelicher et al. 2009). The amplitude, frequency, and mechanisms of the AMOC multidecadal fluctuations are model dependent. For example, some, but not all, models show statistically significant peaks in their AMOC power spectrum at periods ranging from 20 to more than 100 years (e.g., Fig. 1; Weaver et al. 1991; Delworth et al. 1993; Dong and Sutton 2001). From a dynamical system perspective, the AMOC variability can be explained by several alternative scenarios. First, AMOC variability may be due to damped ocean modes stochastically excited by atmospheric variability: for example, a single damped oscillatory mode producing a sharp spectral peak (e.g., 


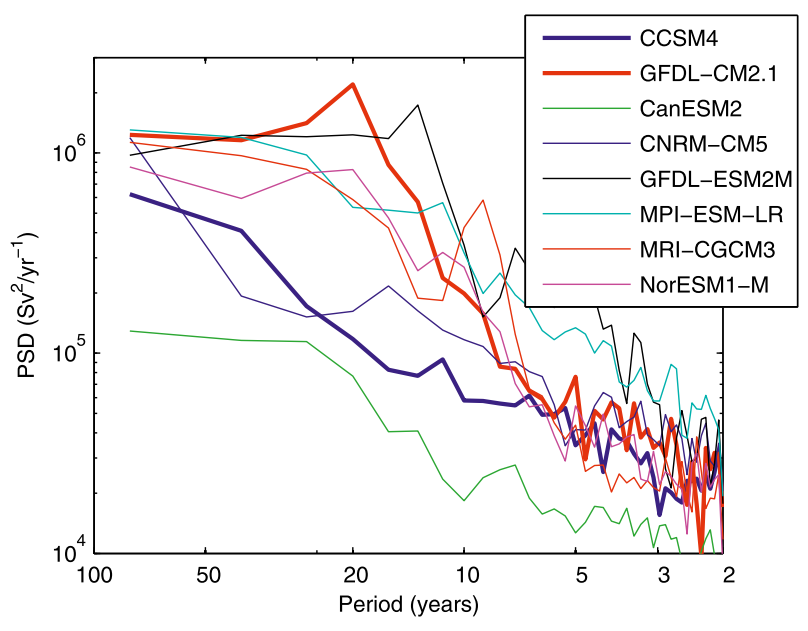

FIG. 1. Power spectrum of AMOC variability, with the AMOC index computed as the amplitude of the first EOF of the meridional overturning streamfunction (see section 2 for the motivation for this definition; note that the scaling of AMOC index here depends on the EOF normalization described in the text). The two models considered here in more detail, CCSM4 and GFDL CM2.1, are shown with thicker lines.

Delworth et al. 1993; Griffies and Tziperman 1995), reddening of the spectrum with no preferred frequency (e.g., Frankignoul and Hasselmann 1977; Cessi 1994), or the interaction between several damped nonnormal modes (Lohmann and Schneider 1999; Tziperman and Ioannou 2002; Zanna and Tziperman 2005; Alexander and Monahan 2009). Second, the variability may be due to self-sustained oscillatory modes of the ocean (e.g., Winton and Sarachik 1993; Weaver et al. 1993; Greatbatch and Zhang 1995; Chen and Ghil 1995). Finally, coupled ocean-atmosphere modes may also lead to AMOC variability (e.g., Timmermann et al. 1998; Xiuhua and Jungclaus 2008).

The AMOC may vary on decadal time scales because of external forcing factors such as heat and freshwater fluxes, the North Atlantic Oscillation (NAO), or internal factors such as deep convection, overflows, or winddriven gyre strength (e.g., Delworth et al. 1993; Weaver et al. 1993; Griffies and Tziperman 1995; Delworth and Greatbatch 2000; Bryan et al. 2006; Bjerknes 1964; Kushnir 1994; Marshall et al. 2001; Yeager and Danabasoglu 2012). Different mechanisms are brought forward for explaining AMOC variability in different models and sometimes even in the same model. For example, Zhang (2008) suggested that the decadal peak in AMOC variability from the GFDL CM2.1 control run is likely linked to freshwater fluxes, while Frankcombe et al. (2009) considered the variability to be dictated by the westward propagation of subsurface temperature anomalies as baroclinic Rossby waves. When the same historical forcing is applied to different models, SST and AMOC variability are not better constrained, and a large multimodel spread in mean and variability of the Atlantic Ocean still remains over the twentieth century (Solomon et al. 2007). For example, using 10 models from the Coupled Model Intercomparison Project phase 5 (CMIP5) archive under historical forcing, Cheng et al. (2013) found AMOC multidecadal fluctuations with peak-to-peak amplitude varying between a few tenths of a Sverdrup ( $\mathrm{Sv} ; 1 \mathrm{~Sv} \equiv 10^{6} \mathrm{~m}^{3} \mathrm{~s}^{-1}$ ) to several Sverdrups, depending on the model. None of the proposed AMOC variability mechanisms can be verified or ruled out using observations due to the short time series and sparsity of the observational AMOC record (Cunningham et al. 2007). To date, the driving mechanisms of AMOC decadal fluctuations and what sets their dominant period, if any, remain largely unresolved. Whether or not aerosols and solar forcing play a role in the Atlantic multidecadal variability (Booth et al. 2012), it is very likely that diverse AMOC variability patterns and proposed mechanisms in numerical simulations point toward systematic errors in climate models.

Model errors, systematic or random, have been identified as the primary source of uncertainty for decadal predictions and centennial projections of climate change (Palmer 2001; Hawkins and Sutton 2009). Griffies and Bryan (1997) showed that the internal variability of North Atlantic Ocean temperature and AMOC in a coupled ocean-atmosphere GCM is potentially predictable up to a couple of decades ahead, due to the enhanced power at this frequency. However, the potential predictability and forecast skill of the North Atlantic climate is model dependent. Reducing uncertainties in decadal predictions via the use of data assimilation to initialize decadal forecasts has been the focus of several studies (Smith et al. 2007; Keenlyside et al. 2008). However, there is disagreement on the magnitude and sign of temperature anomaly changes in the North Atlantic. The difference may involve model drift due to the initialization shock (Doblas-Reyes et al. 2011), uncertainty in ocean observations, and most likely model error (Zanna et al. 2011, 2012). A similar spread between model-simulated AMOC and SST under future scenarios is observed (Gregory et al. 2005). Recently, for the representative concentration pathway (RCP4.5) scenario, Cheng et al. (2013) showed that a weakening of the AMOC by the end of twenty-first century is predicted to vary from between $5 \%$ and $40 \%$ of each individual model's historical mean state. Given the lack of agreement between models in their Atlantic decadal variability, one wonders if systematic errors are the cause for discrepancies in AMOC and SST variability under different forcing scenarios (Solomon et al. 2007).

To further understand the spread between model variability patterns, we explore the response of the AMOC 
TABLE 1. Models used, full expansion, and number of simulation years used from their preindustrial control run. CCSM4 data were downloaded directly from the National Center for Atmospheric Research (NCAR) computers, GFDL CM2.1 was downloaded directly from GFDL web portal, and the remaining models were downloaded from CMIP5.

\begin{tabular}{|c|c|c|c|}
\hline Model & Model expansion & Modeling center & $\begin{array}{l}\text { Simulation } \\
\text { length in years }\end{array}$ \\
\hline CCSM4 & Community Climate System Model, version 4 & National Center for Atmospheric Research & 1000 \\
\hline GFDL CM2.1 & $\begin{array}{l}\text { Geophysical Fluid Dynamics Laboratory } \\
\text { Climate Model, version } 2.1\end{array}$ & Geophysical Fluid Dynamics Laboratory & 500 \\
\hline CanESM2 & Second Generation Canadian Earth System Model & $\begin{array}{l}\text { Canadian Centre for Climate Modeling } \\
\text { and Analysis }\end{array}$ & 996 \\
\hline CNRM-CM5 & $\begin{array}{l}\text { Centre National de Recherches Météorologiques } \\
\text { Coupled Global Climate Model, version } 5\end{array}$ & $\begin{array}{l}\text { Centre National de Recherches } \\
\text { Meteorologiques }\end{array}$ & 850 \\
\hline GFDL-ESM2M & $\begin{array}{l}\text { Geophysical Fluid Dynamics Laboratory Earth } \\
\text { System Model with Modular Ocean Model } 4 \\
\text { (MOM4) component (ESM2M) }\end{array}$ & Geophysical Fluid Dynamics Laboratory & 500 \\
\hline MPI-ESM-LR & $\begin{array}{l}\text { Max Planck Institute Earth System Model, } \\
\text { low resolution }\end{array}$ & Max Planck Institute for Meteorology & 1000 \\
\hline MRI-CGCM3 & $\begin{array}{l}\text { Meteorological Research Institute Coupled } \\
\text { Atmosphere-Ocean General Circulation } \\
\text { Model, version } 3\end{array}$ & Meteorological Research Institute & 500 \\
\hline NorESM1-M & $\begin{array}{l}\text { Norwegian Earth System Model, version } 1 \\
\quad \text { (intermediate resolution) }\end{array}$ & Norwegian Climate Centre & 500 \\
\hline
\end{tabular}

to surface forcing in the frequency domain. By examining specific processes within models, one hopes to point to specific model problems. While the causes of the Atlantic multidecadal variability are still debated (Booth et al. 2012; Ting et al. 2009), atmospheric forcing is expected to play a role in the AMOC variability either directly or indirectly. In the present study, we therefore focus primarily on the relationship, in the frequency domain, between AMOC and surface forcing fields, specifically sea surface temperature, sea surface salinity (SSS), and wind forcing. These fields represent heat, freshwater, and momentum fluxes in and out of the ocean. We investigate the relationship using a number of control runs from state-of-the-art climate models from the CMIP5 and Coupled Model Intercomparison Project phase 3 (CMIP3) archive. Frequency domain analysis is the key to understanding critical differences in AMOC spectra in different models. The specific methodology used in this study, borrowed from control engineering (e.g., Astrom and Murray 2008), is transfer function analysis, which describes a dynamic process that relates two variables in the frequency domain. Recently, MacMynowski and Tziperman (2010, 2012, manuscript submitted to Philos. Trans. Roy. Soc.) used transfer function analysis to estimate process dynamics of ENSO in models and observations. Transfer functions relating surface fields to AMOC are calculated here for eight coupled climate models. More detailed analysis is provided for two models, namely CCSM4 (see Table 1 for complete list of model expansions), which has no sharp peak in the power spectrum of AMOC variability, and
GFDL CM2.1, which has a significant peak at around a 20 -yr period. For these two models, additional analysis of subsurface temperature anomalies is used to evaluate specific proposed physical mechanisms for AMOC variability.

The paper is organized as follows. The next section describes AMOC variability in all models considered, followed by an introduction to the transfer function methodology in section 3 . Results highlighting frequencydependent differences between processes in the models are shown in section 4, and an evaluation of two proposed physical mechanisms for AMOC variability is shown in section 5 .

\section{AMOC variability}

We compare the response of AMOC variability to surface forcing of eight state-of-the-art climate model preindustrial control simulations from CMIP5 (Table 1), for which the zonally averaged meridional overturning streamfunction is available. We consider only the Eulerian flow and not the bolus velocity associated with the eddy-induced Gent-McWilliams component.

We are concerned here with AMOC variability on decadal time scales. A commonly used index for AMOC variability is the maximum amplitude of the zonally averaged streamfunction at a given latitude. Power spectra of this index at $26.5^{\circ} \mathrm{N}$ [the latitude of the Rapid Climate Change (RAPID) array; Cunningham et al. 2007; Kanzow et al. 2008; McCarthy et al. 2012] and at $45^{\circ} \mathrm{N}$ [near the West Atlantic Variability Experiment (WAVE) array; 

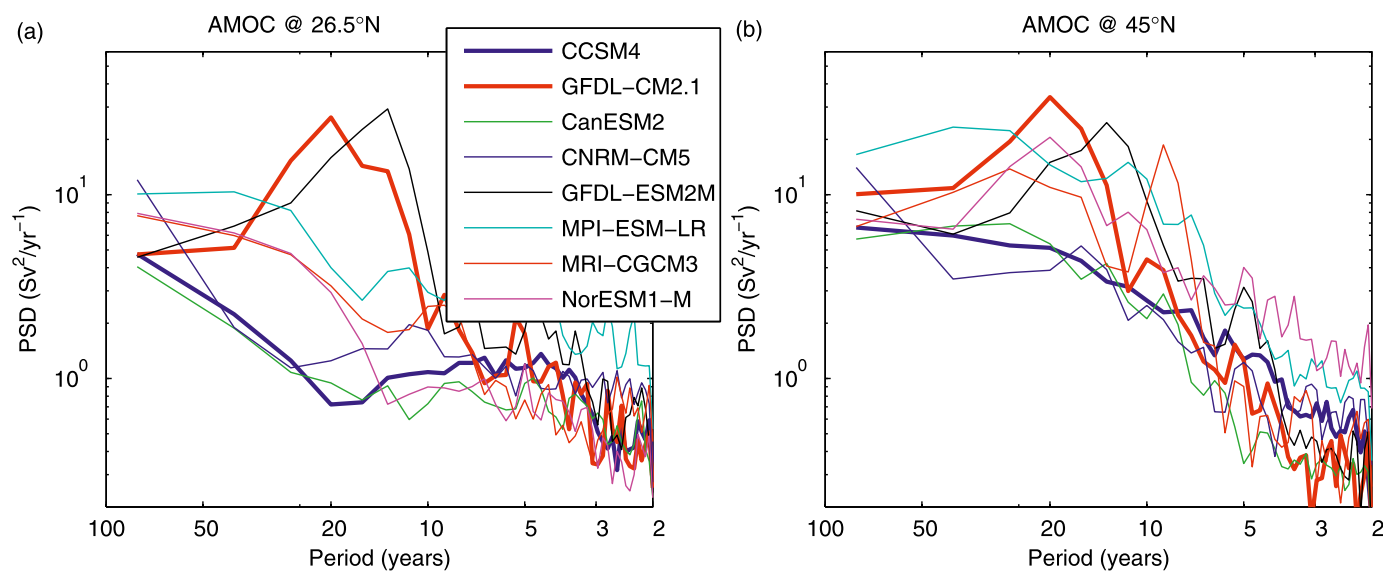

FIG. 2. Power spectrum of AMOC variability at (a) $26.5^{\circ}$ and (b) $45^{\circ} \mathrm{N}$.

Elipot et al. 2013; Bingham et al. 2007] from each of the eight models considered in this study are shown in Fig. 2. At $26.5^{\circ} \mathrm{N}$, both of the Geophysical Fluid Dynamics Laboratory (GFDL) models, CM2.1 and ESM2M, exhibit very large peaks in their power spectrum around 15-20-yr periods, setting them apart from all other models. At $45^{\circ} \mathrm{N}$, NorESM1-M also exhibits a spectral peak at a $20-y r$ period whereas MRI-CGCM3 has a narrow peak at an 8-yr period. While the presence or absence of strong spectral peaks is the most obvious qualitative difference between the models, there are significant differences in the predicted amplitude of AMOC variability even among the models that do not have any statistically significant spectral peak.

An alternate way to characterize variability is to consider the time series associated with the empirical orthogonal functions (EOFs) of the overturning streamfunction over the North Atlantic, shown in Fig. 3 for GFDL CM2.1. To focus on the patterns associated with variability on decadal time scales, we low-pass filter the streamfunction before computing the EOFs, using a noncausal second-order filter with a cutoff frequency corresponding to a 5-yr period. All EOFs are normalized to unit average mean-square value integrated over depth and over latitude from $0^{\circ}$ to $75^{\circ} \mathrm{N}$; this determines the scaling of our AMOC index. The first EOF captures more than $50 \%$ of this low-frequency variance in all models and $80 \%$ of the variance in CCSM 4 and CNRM-CM5. The EOF patterns are broadly similar for all eight models, with the first EOF corresponding to a change in overall strength (Fig. 3a); the sign of the first EOF is chosen so that the projection of the streamfunction onto this EOF is positive. The second EOF pattern reflects a north-south shift (Fig. 3b), and the third (not shown) characterizes a shift in the depth of the peak overturning (for CCSM4 and CNRM-CM5, the order of the second and third EOFs is reversed, although neither contains significant power for these two models).

The second EOF of the GFDL CM2.1 model, which reflects the north-south shift in the overturning circulation, only captures roughly $15 \%$ of the total variance, but almost all of its spectral energy is contained in a narrow frequency band between 15 - and 20 -yr periods. In contrast, the first EOF spectral peak at a 20 -yr period is much less pronounced. Thus, the pronounced GFDL streamfunction spectral peaks at either $26.5^{\circ}$ or $45^{\circ} \mathrm{N}$ are largely due to the projection onto the second EOF and are therefore associated more with a north-south shift of the cell and to a lesser degree with a change in circulation strength. Such a result is consistent with recent studies suggesting observed opposing decadal changes of subtropical and subpolar circulation (Lozier et al. 2010). We will adopt the amplitude of the projection onto the first EOF of the meridional overturning streamfunction, reflecting changes in the circulation amplitude, as our definition of the AMOC index for the remainder of the paper, with the power spectra for this index shown in Fig. 1. Similar to the GFDL models, the narrow peak near the 8-yr period in MRI-CGCM3 is associated with both amplitude changes (first EOF) and a shift in latitude (second EOF). On the other hand, the peak in the power spectrum for NorESM1-M is associated primarily with a change in the overturning amplitude (first EOF).

Having better understood the nature of the frequency-dependent variability in Figs. 1 and 2, we now turn to the frequency domain in order to understand some of the responsible processes. We first introduce the concept of a transfer function to be used in section 4 in order to analyze processes influencing AMOC variability. 
(a)

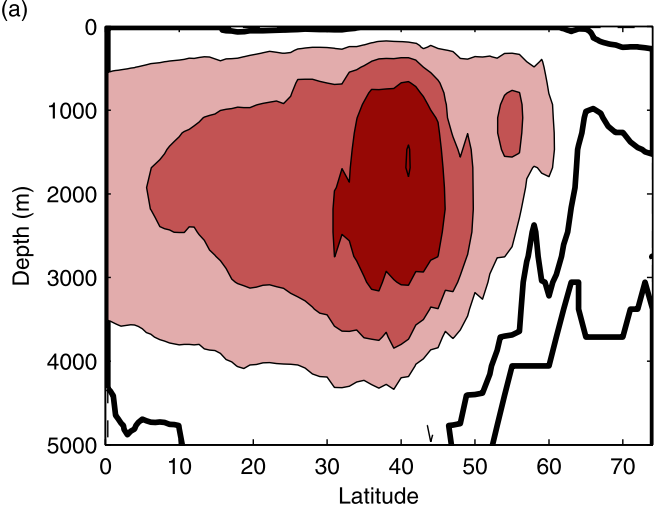

(c)

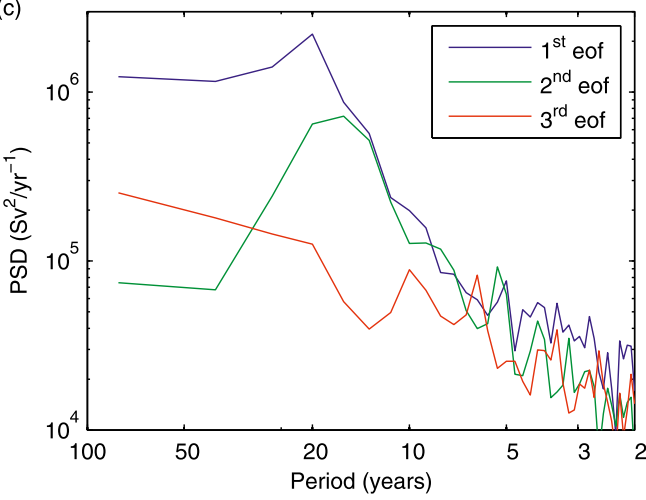

(b)

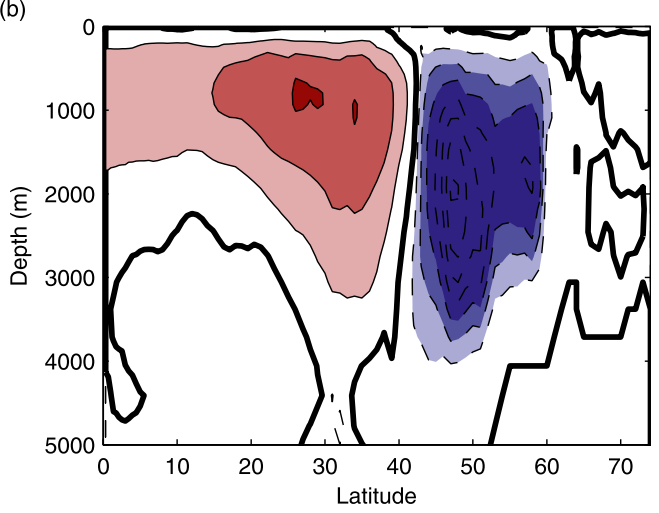

(d)

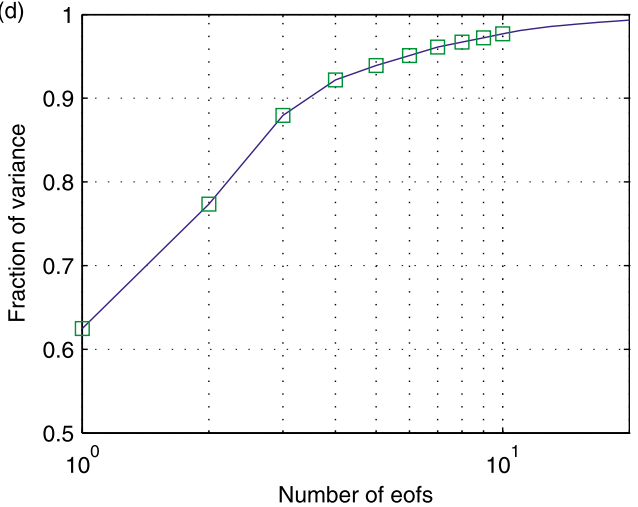

FIG. 3. EOFs of meridional overturning streamfunction for GFDL CM2.1: (a) first and (b) second EOF pattern with contour intervals equal to $1 \times 10^{-3}$ (blue shading if $<-1 \times 10^{-3}$, red shading if $>1 \times 10^{-3}$; thick line for the zero contour). (c) Power spectrum of streamfunction projected onto first three EOFs. (d) Fraction of variance captured by each EOF.

\section{Transfer function methodology}

Transfer functions describe the linear frequencydependent response of an output variable to perturbations in an input variable (e.g., Astrom and Murray 2008). Given a differential equation describing the relationship between input variable $x$ and output variable $y$, the transfer function can be defined using the Laplace or Fourier transforms of these variables. For example, if $d y / d t=a x-b y$ for some $a$ and $b, \hat{y}(f)$ is the Fourier transform of $y(t)$ given the frequency $f$ and $s=2 \pi i f$, then the transfer function $T(s)$ is $T(s) \equiv \hat{y}(s) / \hat{x}(s)=a /(s+b)$ [i.e., $\hat{y}(s)=T(s) \hat{x}(s)$ ]. In general, the transfer function describes how a scalar output signal (e.g., AMOC strength or $y$ above) depends on perturbations in any input (e.g., the amplitude of some particular spatial pattern of SST or of wind stress or $x$ above).

Two other simple transfer functions forms are shown in Fig. 4, corresponding to the differential equations

$\ddot{\mathrm{y}}+b \dot{y}+b^{2} y=a b x \Rightarrow T(s)=\frac{a b}{s^{2}+b s+b^{2}} \quad$ and

$$
\dot{q}=a x-b q, \quad y=q-c x \Rightarrow T(s)=\frac{a}{s+b}-c .
$$

These are useful in interpreting the results of GCM analyses in section $4 \mathrm{~b}$ (see, e.g., Fig. 8), as they illustrate two possible differential equations that are consistent with a $180^{\circ}$ phase shift between low and high frequencies while the transfer function magnitude decreases with frequency.

The analysis here estimates the frequency-dependent transfer function directly from the time series of the chosen input and output (e.g., section 6.2, Swanson 2000). Given input and output time series $x(t)$ and $y(t)$ and their Fourier transforms $\hat{x}(f)$ and $\hat{y}(f)$, the transfer function can be estimated as the ratio of cross correlation to the autocorrelation in the frequency domain:

$$
T_{x y}(f)=\frac{\left\langle\hat{x}^{*}(f) \hat{y}(f)\right\rangle}{\left\langle\hat{x}^{*}(f) \hat{x}(f)\right\rangle}=\frac{S_{x y}(f)}{S_{x x}(f)} .
$$

The autocorrelations and cross correlations $S_{x x}(f)$ and $S_{x y}(f)$ are estimated by (i) dividing the time series for $x$ 

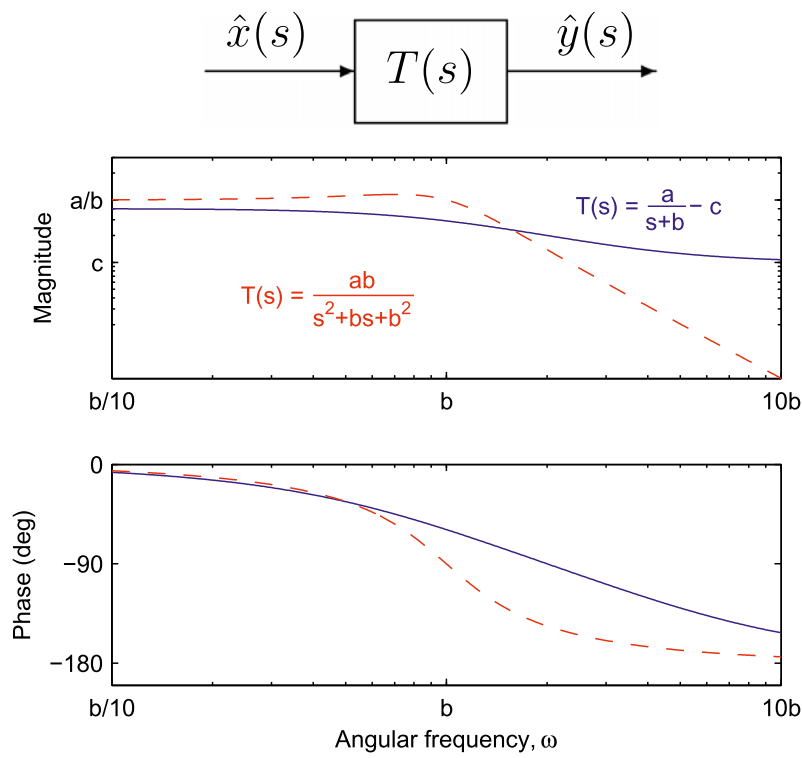

FIG. 4. Example illustrating transfer function characteristics for the two systems in Eqs. (1) and (2) that both have a $180^{\circ}$ phase shift between low and high frequencies and a magnitude decreasing with frequency (cf. with Fig. 8).

and $y$ into $n$ possibly overlapping segments of smaller length, $x_{k}(t)$ and $y_{k}(t)$; (ii) computing the Fourier transforms $\hat{x}_{k}(f)$ and $\hat{y}_{k}(f)$ of each of the windowed signals $x_{k}(t)$ and $y_{k}(t)$ in the $k$ th segment and calculating their products in each segment; and (iii) averaging these products over the segments to calculate the correlations in Fourier space:

$$
S_{x y}(f)=\frac{1}{n} \sum_{k=1}^{n} \hat{x}_{k}^{*}(f) \hat{y}_{k}(f) .
$$

With sufficient averaging, only the contribution due to the part of the output signal that is correlated with the input signal will remain. The error in estimating $T_{x y}$ due to the uncorrelated component of the output can be estimated from the coherence [Eq. (6.2.21) and (6.2.22) of Swanson (2000); see also MacMynowski and Tziperman (2012, manuscript submitted to Philos. Trans. Roy. Soc.)]:

$$
\gamma_{x y}^{2}(f)=\frac{\left|S_{x y}(f)\right|^{2}}{S_{x x}(f) S_{y y}(f)} .
$$

Increasing the averaging by dividing the signal into more but shorter segments results in a smaller resolved frequency range. To resolve this, we use a different number of data segments to estimate the transfer function at different frequencies, allowing us to increase the averaging at high frequencies while still estimating the response at low frequencies.
The transfer function is in general complex and both its magnitude and phase, $\Phi(f)$, provide useful information:

$$
T_{x y}(f)=\left|T_{x y}(f)\right| e^{i \Phi(f)} .
$$

The magnitude describes the strength of the relationship, while the phase indicates the lead or lag between the input and output variables as a function of frequency, providing clues about causality. Lag correlations can also be used to estimate an average time lag between two signals, although they are unable to do so for each frequency separately. If both signals are first passed through a narrow bandpass filter, then the lag-correlation plot yields similar information to the transfer function phase: zero phase lag corresponds to a correlation plot having a peak at zero time lag, while a negative transfer function phase corresponds to a delay, that is, a peak in the correlation corresponding to the output signal having a positive time lag relative to the input. A positive transfer function phase is thus often due to the input signal being caused by the output. Of course, all of the processes we are interested in involve influences in both directions: for example, variations in surface salinity influence $\mathrm{AMOC}$ and variations in $\mathrm{AMOC}$ due to other mechanisms also influence the salinity. We use the transfer function phase to suggest which direction of influence is dominant in any given frequency band, although this is not definitive (e.g., a $90^{\circ}$ phase lag might indicate the output lagging the input or could also result from an opposite lag but with a sign change). An explicit fit of the transfer function to the underlying differential equation would be required to fully interpret the dynamical relationship, although this is neither straightforward for the relationships examined here nor necessary to gain insight here into AMOC variability.

Linear inverse modeling (LIM; Penland Sardeshmukh 1995) can also describe the input-output relationship. However the functional form of the relationship is assumed a priori in LIM (typically a first-order differential equation relating inputs and output), while the transfer function approach is model free and thus provides further insight into the actual frequency dependence of the relationship.

\section{Transfer function analysis of the relation between surface forcing and AMOC}

We consider the influence of SST, SSS, and the magnitude of wind stress (TAU) on AMOC variability. It is possible to analyze the influence of freshwater and heat fluxes on the AMOC. However, a difference between two models could then be attributed to either the effects 
(a)

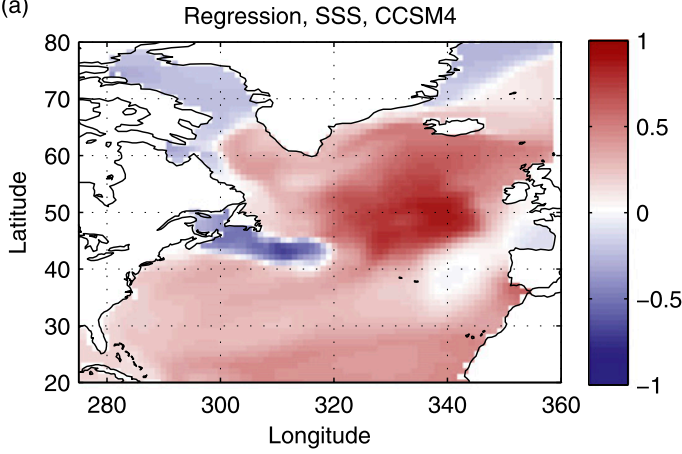

(c)

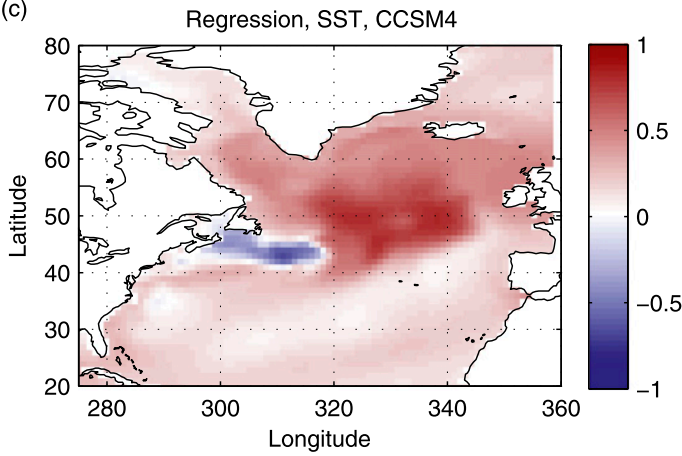

(e)

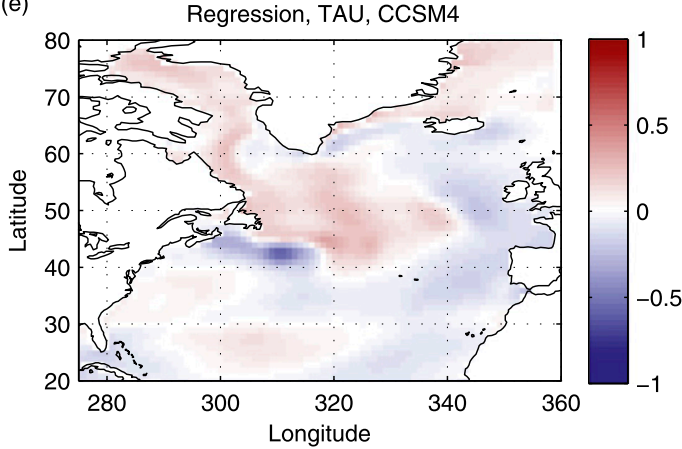

(b)

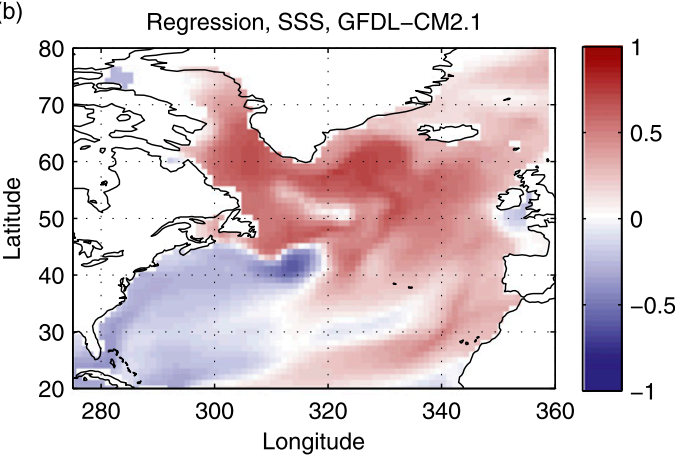

(d)

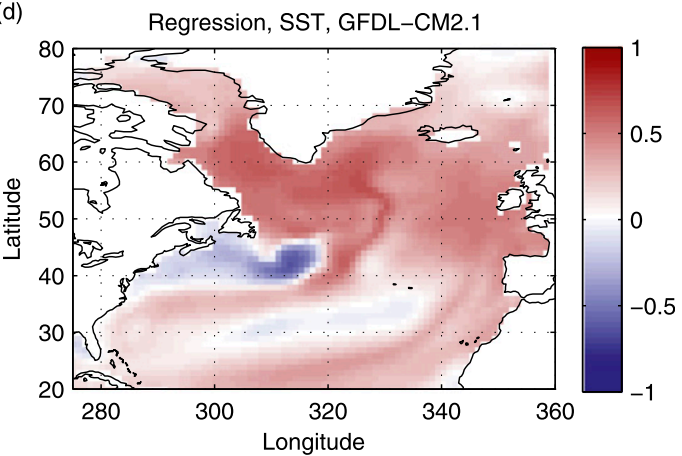

(f)

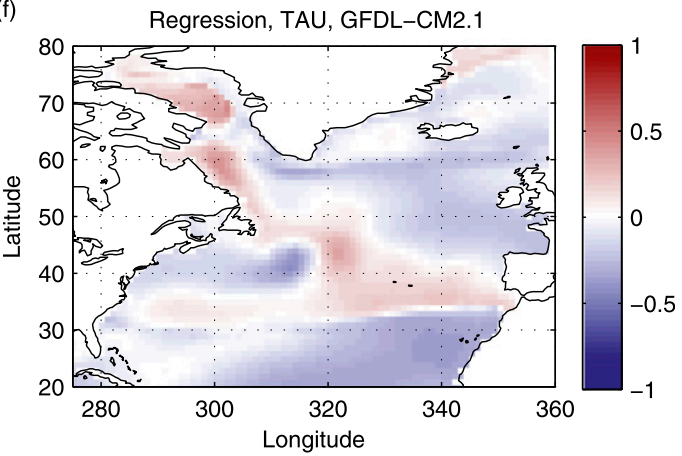

FIG. 5. Regression patterns for (left) CCSM4 and (right) GFDL CM2.1, for (top) SSS, (middle) SST, and (bottom) wind stress magnitude. The EOFs for SSS for these two models are compared in Fig. 7. The regression patterns for SSS for the remaining six models considered here are shown in Fig. 6.

of, say, heat fluxes on SST or to the effects of the SST on the AMOC. This could potentially complicate the interpretation of the results. In addition, we found that the transfer functions from surface fluxes of freshwater and heat to AMOC have a small signal-to-noise ratio and that the direction of causality was not clear. We have therefore opted to use SST and SSS fields instead of the surface fluxes.

We start with an in-depth comparison of two models: GFDL CM2.1, which has a clear peak in the AMOC variability power spectrum, and CCSM4, which does not. These two models therefore capture opposite ends of the range of AMOC variability on decadal time scales.

\section{a. Spatial analysis via regression patterns}

We first need to identify the spatial patterns of variations in SST, SSS, and TAU that are related to AMOC variability. We will use these spatial patterns to create a scalar index for the frequency domain transfer function analysis. Consider the regression pattern of the three surface fields onto the AMOC for CCSM4 and GFDL CM2.1 shown in Fig. 5. One striking feature is the tongue appearing in all forcing fields around $45^{\circ} \mathrm{N}$, starting from the North American coast. This latitude is significant to the AMOC variability, being both the boundary between the subtropical and subpolar gyre and the zero-crossing 
(a)

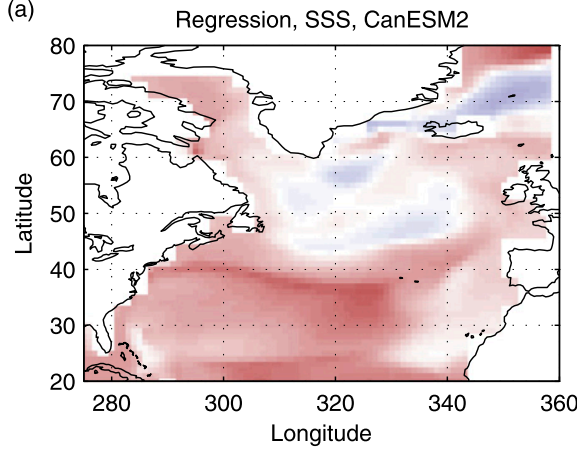

(c)

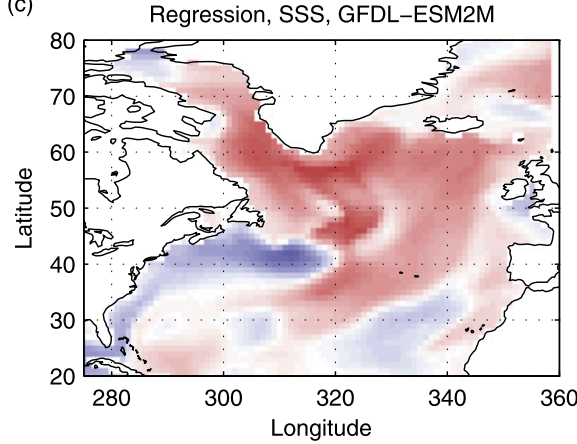

(e)

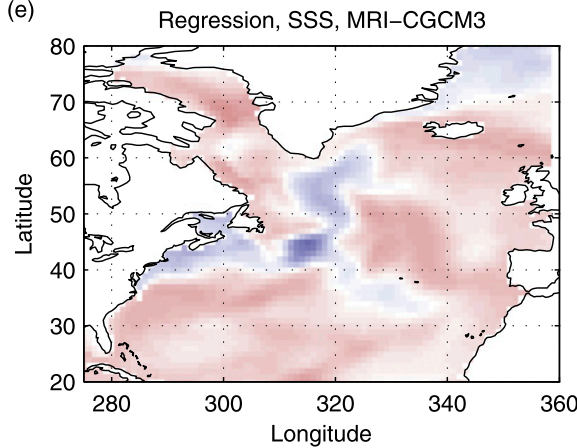

(b)
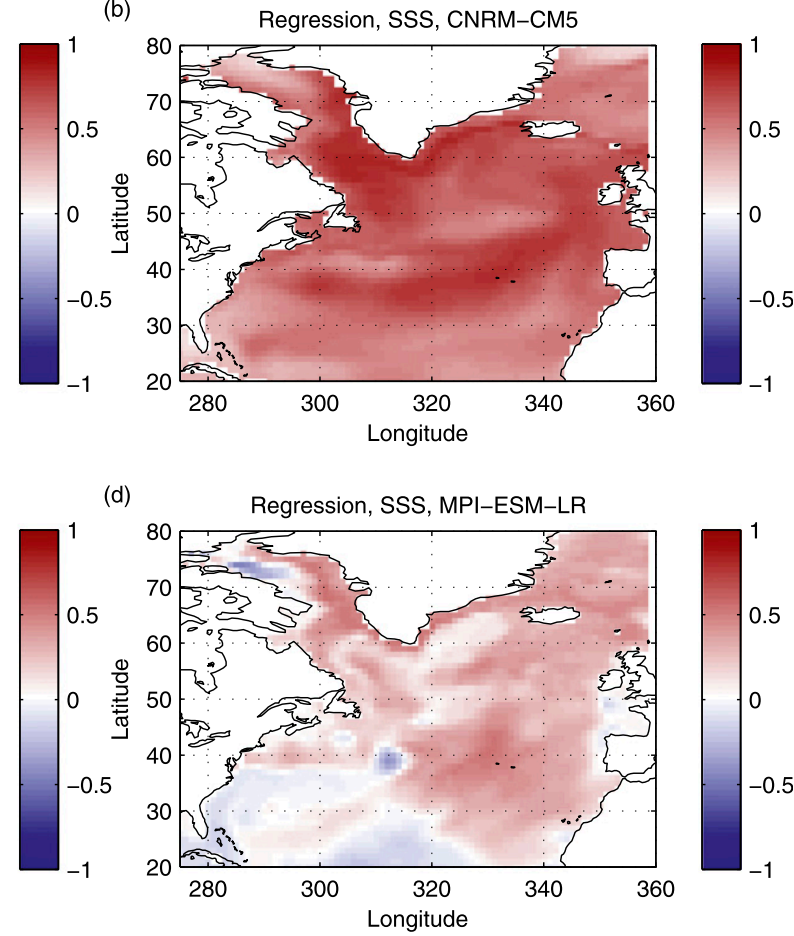

(d)
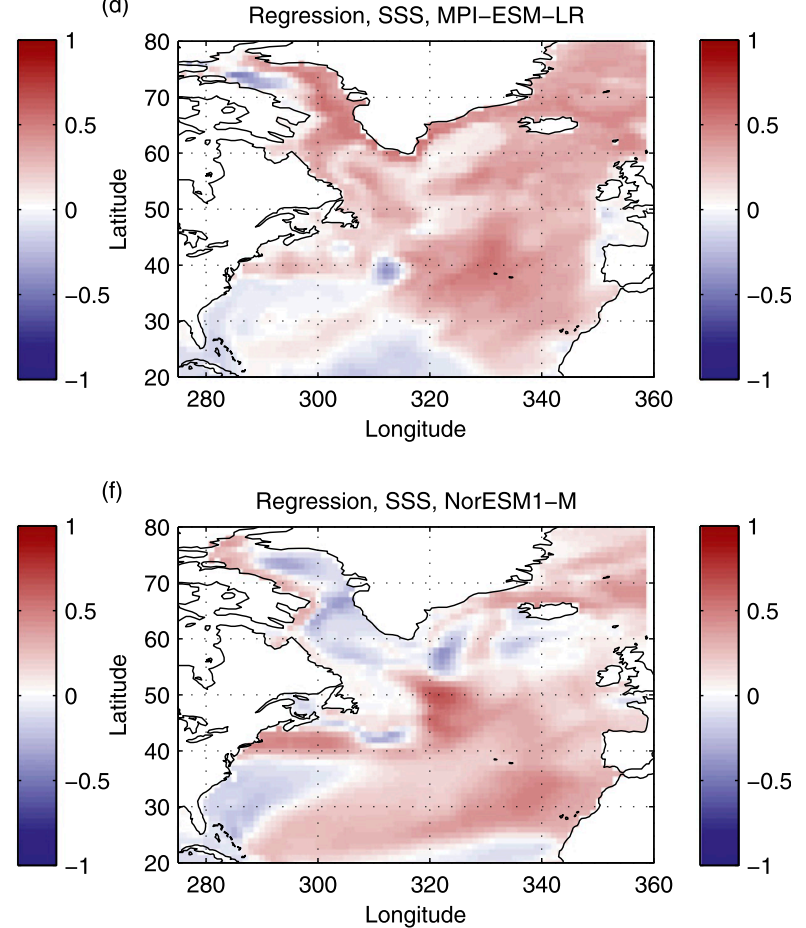

(f)

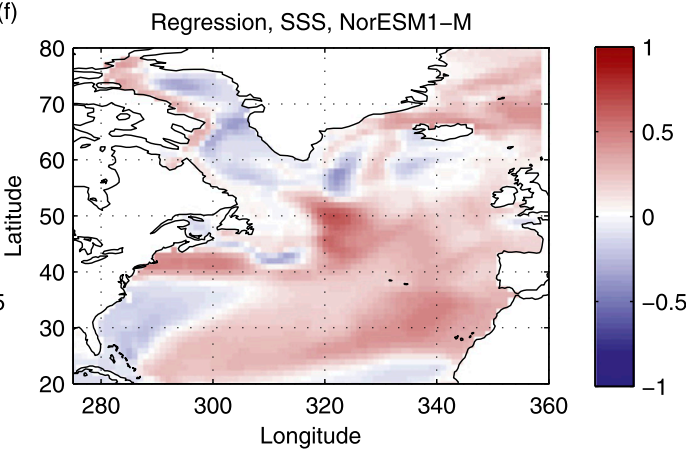

FIG. 6. Regression patterns for SSS for (a) CanESM2, (b) CNRM-CM5, (c) GFDL-ESM2M, (d) MPI-ESM-LR, (e) MRI-CGCM3, and (f) NorESM1-M.

latitude for the second EOF, possibly indicating that it is a region where the variability may be excited (Tulloch and Marshall 2012; Buckley et al. 2012; Zanna et al. 2012). The similarity between SST and SSS patterns indicate that density is the important factor in forcing AMOC variability in the models. Moreover, the presence of an anomaly near the $45^{\circ} \mathrm{N}$ latitudinal band seen in the wind regression pattern may mean that the wind is able to excite density variability in this area. While the regression patterns are similar for the two models analyzed above, this does not hold across all models, as seen in the SSS regression patterns for the remaining six models shown in Fig. 6.

It is especially interesting that the regression patterns $R(x, y)$ are similar to the first EOF of the surface fields,
$E(x, y)$, shown for example for SSS in Fig. 7 (after lowpass filtering to focus on low-frequency variability). Note that the normalized correlation between the EOF and regression pattern [i.e., $\int_{A} E(x, y) R(x, y) d A$ integrated over the plotted region of the North Atlantic, then normalized by the root-mean-square of $E$ and $R]$ is $\sim 0.75$ for either model, while a similar normalized correlation of either the EOFs or regression patterns between these two models is only about 0.4 . That is, the EOF for each model is quantitatively more similar to the regression pattern for that model than it is to the EOF of the other model. Nonetheless, it is the qualitative agreement that we are concerned with here.

Consider some limiting cases to understand the expected relationship between the SSS regression and 
(a)

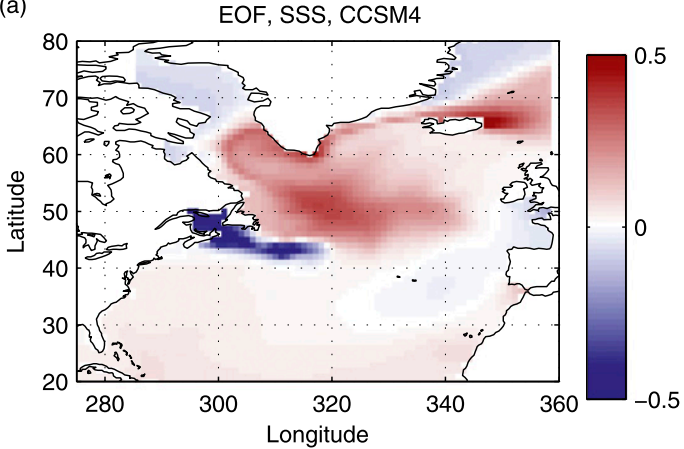

(b)

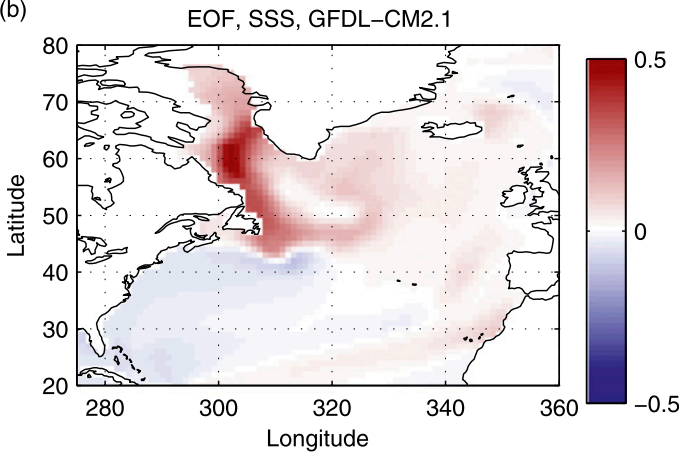

FIG. 7. First EOF of low-frequency SSS variability for (a) CCSM4 and (b) GFDL CM2.1.

EOF patterns. Suppose first that SSS anomalies influence AMOC variability but that they are not affected by the AMOC. Because salinity is forced by other factors, there is no reason to expect SSS variability patterns (EOFs) to project strongly onto the pattern that forces the AMOC (represented by the regression pattern in this scenario). If, on the other hand, SSS anomalies are forced mostly by AMOC variability, then one expects SSS variability patterns (EOFs) to be similar to regression pattern of SSS and AMOC. The agreement between regression and EOF patterns in the models analyzed here (cf. Figs. 5 and 7) is thus an indication that AMOC variability likely affects SSS anomalies and that the opposite relation cannot be ruled out. The first EOF for SST (not shown) is also similar to the corresponding regression pattern, while the first EOF of variability in the wind stress magnitude (not shown) does not show any similarity to the regression pattern in Fig. 5, suggesting that the wind stress variability influences AMOC variability but is not strongly influenced by it. Therefore, AMOC does not feed back onto the atmospheric wind patterns (such as the NAO) in the model considered.

The regression patterns in Fig. 5 indicate the pattern of each variable that is most likely to be related to AMOC variability. Given the spatial regression patterns of SST, SSS, and wind stress magnitude, we project the full fields onto these patterns to create three scalar indices for each model. The scalar indices can then be used as the input for the transfer function, with the output being the AMOC index previously defined. Note that we can either project each model SST onto its own regression field or on a common regression field obtained, for example, from the average of the different patterns. The two approaches test different questions, and each has its own advantages. Using individual model patterns, a difference in the transfer function between models might result from the different spatial regions being considered, yet each transfer function more accurately reflects the relation between surface forcing and AMOC for a given model. Using a common pattern provides consistency across models, but a model may have a different transfer function not because the underlying processes differ but simply because the processes occur at a different spatial location.

For CCSM4 and GFDL CM2.1, the SST and SSS regression patterns are sufficiently similar so that we can use the average regression pattern (Fig. 8). We find that the conclusions from transfer function analysis are similar if the individual or averaged regression patterns are used, and thus only the results from the average pattern are shown. However, the regression patterns for the wind stress are too different for the average pattern to be meaningful, as are the regression patterns for SST and SSS when considering all eight models (Fig. 6). We note that many of the regression patterns are dominated by northern latitudes (Figs. 5a-d), and so we consider input indices based on a simple average over $50^{\circ}$ to $70^{\circ} \mathrm{N}$ and from $300^{\circ}$ to $350^{\circ} \mathrm{E}$ (Fig. 9c). This index is used for wind regression patterns for all eight models and for SSS and SST when all eight models are considered (Fig. 10; this choice will be described further below.)

\section{b. Transfer functions}

We first project the surface fields onto the average (model independent) SST and SSS regression patterns as described above and consider the transfer function to AMOC. The average regression pattern and corresponding transfer functions are shown in Fig. 8 for GFDL CM2.1 and CCSM4. For these processes, these two models are reasonably consistent at very low frequencies (periods of 40 years and longer). However, differences between the transfer functions for these two models are immediately apparent in the frequency range of 10-30 years, where the GFDL model has a significant spectral peak in the AMOC variability. This is a critical observation, indicating that the different AMOC variability between the two models may be related to differences in how strongly AMOC responds to perturbations in the surface 

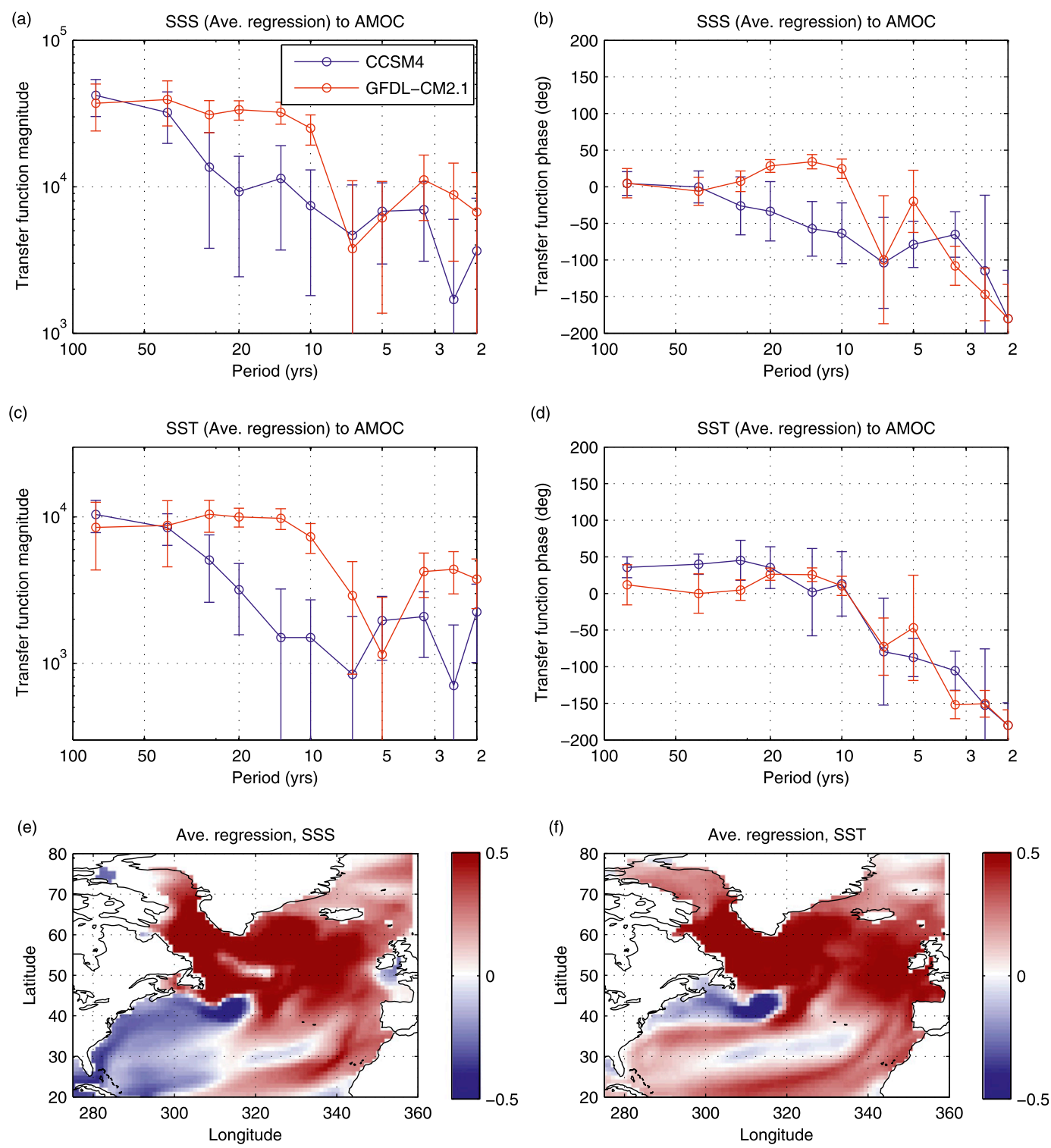

FIG. 8. CCSM4 and GFDL CM2.1 transfer functions to AMOC index from the average regression pattern (shown at bottom) for SSS (a) magnitude and (b) phase and for SST (c) magnitude and (d) phase. The $\pm 2-\sigma$ error bars are estimated from the coherence. Average regression pattern for (e) SSS and (f) SST.

fields in this frequency regime. We note that the uncertainty in the transfer function estimates at high frequencies (periods shorter than 10 years) that are not our focus here can be significant, as indicated by the error bars. Nonetheless there is arguably better agreement between the models in periods shorter than 10 years than for periods of 10-30 years.

A few additional observations can be made regarding the transfer functions. First, the error bars are smaller for the GFDL model than CCSM4, despite the shorter simulation, because the variance is much higher, and the coherence between the signals is much higher (a larger fraction of the AMOC variability is correlated with the surface variability). Second, the $180^{\circ}$ phase shift between low and high frequencies observed in both models could result either from exciting an ocean oscillatory mode [e.g., Eq. (1)] or from different physical processes with opposite signs being dominant at low frequencies versus high [e.g., Eq. (2), with the two physical processes being $a /(s+b)$ and the term $-c$ with its opposite sign]. The excited oscillatory mode mechanism implies that the transfer function amplitude drops rapidly with frequency (Fig. 4), but this does not seem to be the case in the GCM transfer functions shown in Fig. 8. A time 


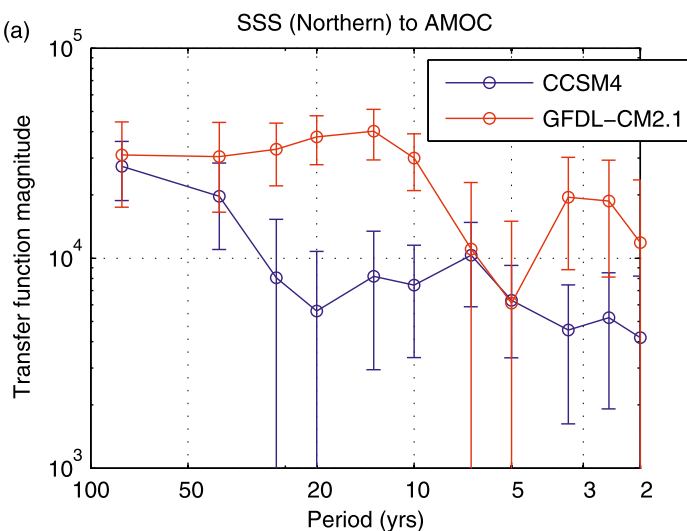

(c)

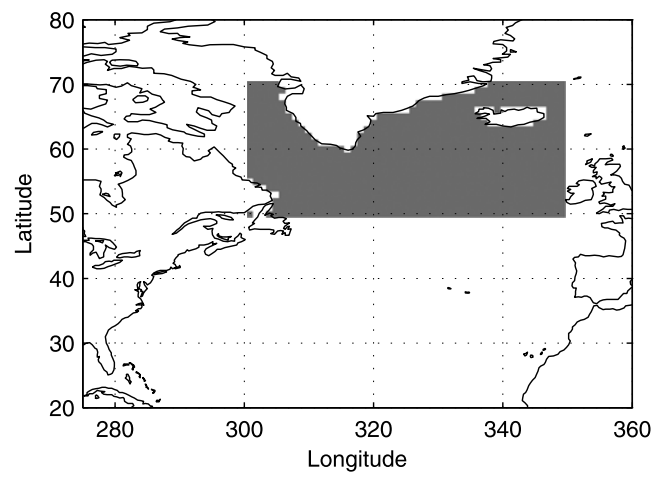

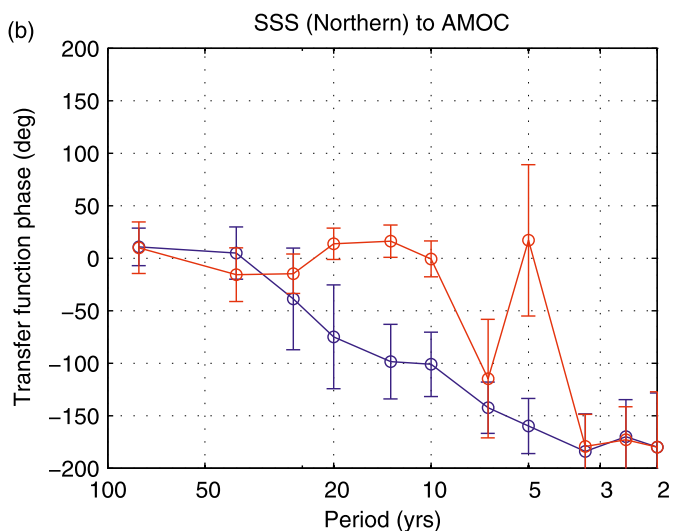

(d)

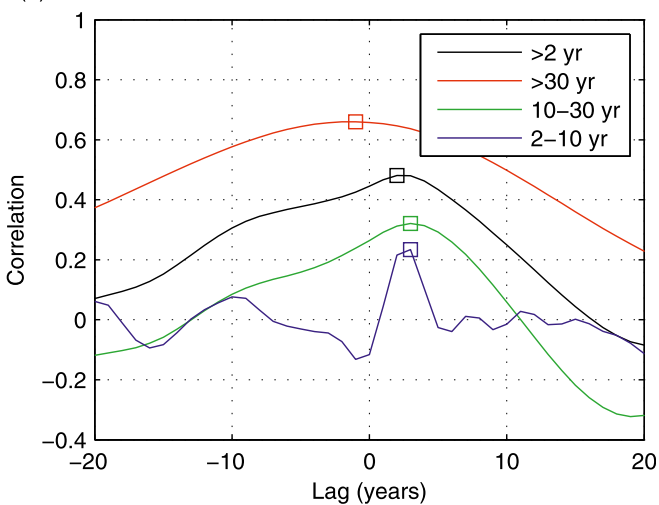

FIG. 9. Transfer function from high-latitude SSS to AMOC index for CCSM4 and GFDL CM2.1. (a),(b) The magnitude and phase with $\pm 2-\sigma$ error bars estimated from the coherence. (c) The SSS is averaged over the shaded region. (d) The lag correlation from the SSS to AMOC index for CCSM4, with different bandpass filters to highlight the delay in different frequency regimes: a phase of zero in (b) corresponds to zero time delay, while a phase lag in (b) corresponds to the peak correlation in (d) occurring at positive time lag (SSS anomalies leading AMOC anomalies). For GFDL CM2.1, the correlations are maximized near zero lag for all frequency bands, consistent with the phase in (b).

delay would also give a frequency-dependent phase, but the magnitude would be uniform with frequency, again not consistent with the GCM results. However, the dynamic relationship between SST and AMOC and SSS and AMOC is likely more complicated than the simple differential Eqs. (1) and (2), limiting our ability to determine precisely the reason for the $180^{\circ}$ transfer function phase range across frequencies. But as we show here, transfer function differences between models are a useful diagnostic, even when the precise underlying equations are not known.

As noted above, the average regression pattern of SST and SSS cannot be used for considering all other models nor for the wind stress. We therefore consider the spatial average over $50^{\circ}$ to $70^{\circ} \mathrm{N}$ and from $300^{\circ}$ to $350^{\circ} \mathrm{E}$ (shown in Fig. 9c). As a first step, we verify that the resulting transfer functions for CCSM4 and GFDL CM2.1 using the high-latitude index (Fig. 9) are similar to the transfer functions computed with the average regression pattern (Figs. 8a-d). This confirms that the northern region considered captures most of the dynamically relevant coupling between the surface fields and AMOC variability identified through the regression analysis.

Figure 9d shows the lag correlation for CCSM4 after bandpass filtering the signals in different frequency regions. At very low frequencies (long periods), SSS and AMOC perturbations are roughly in phase, consistent with the zero phase lag in the transfer functions. At higher frequencies (shorter periods, $10-30$ years), there is a clear lag of a few years between SSS perturbations and AMOC variation, again consistent with the transfer function phase shown in Fig. 9b at periods of 10-30 years. The use of the transfer function phase lag to suggest causality relationships is thus consistent with the lagcorrelation information. Note that lag correlation based on the full signal without bandpass filtering combines the effects of all frequency bands, making it more difficult to assess the direction of causality. The zero phase lag at low to midfrequencies (10-30 years in particular, Fig. 9b) for the SSS to AMOC GFDL transfer function indicates that 

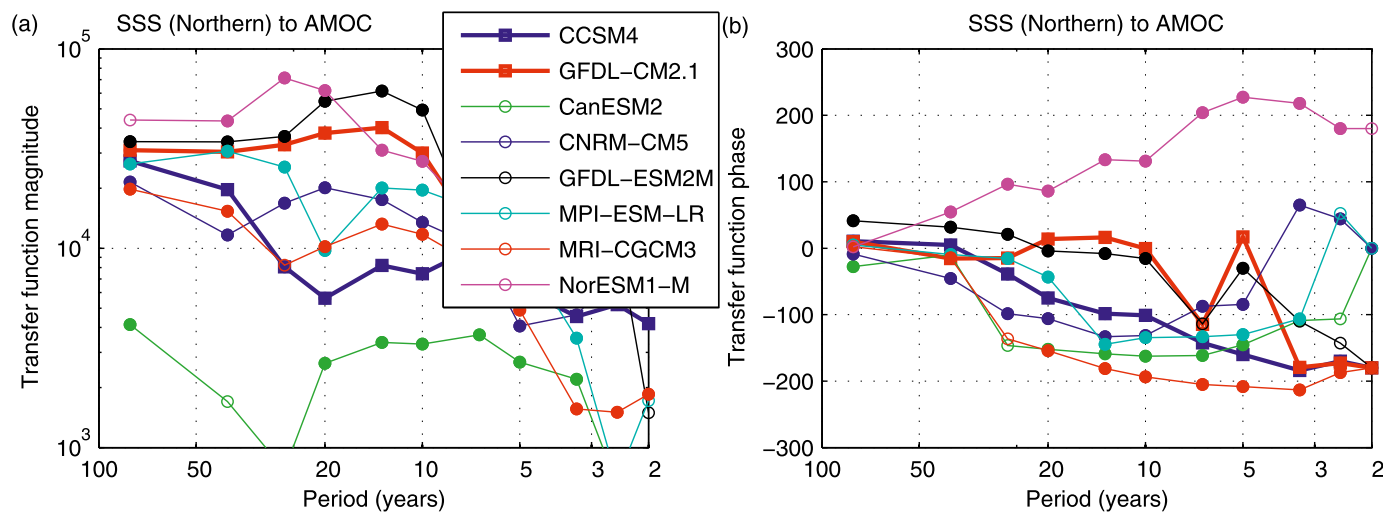

(c)
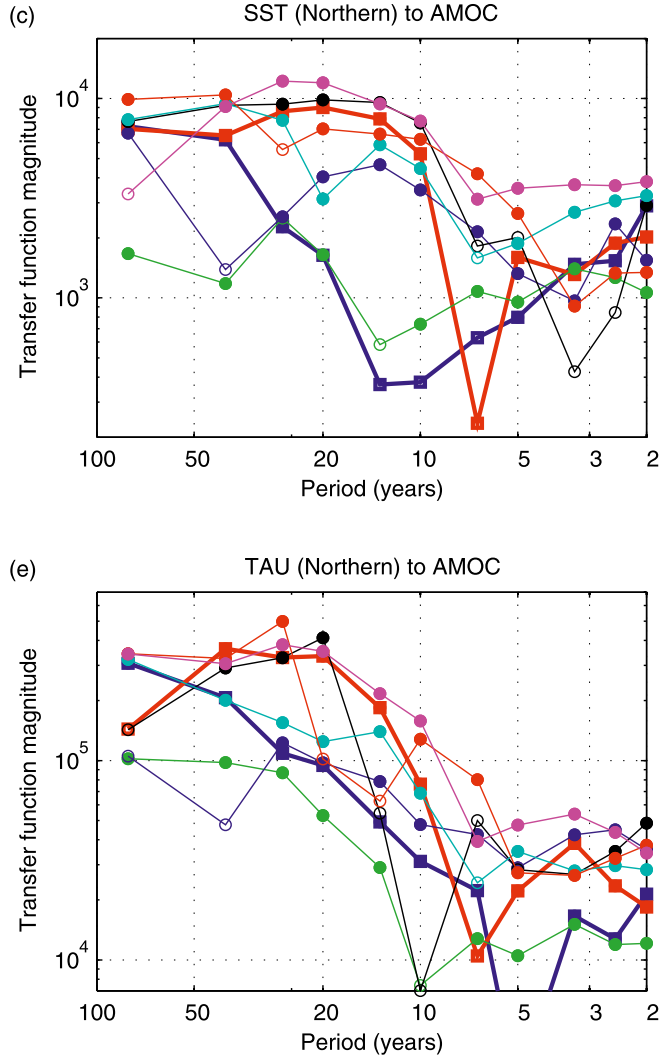
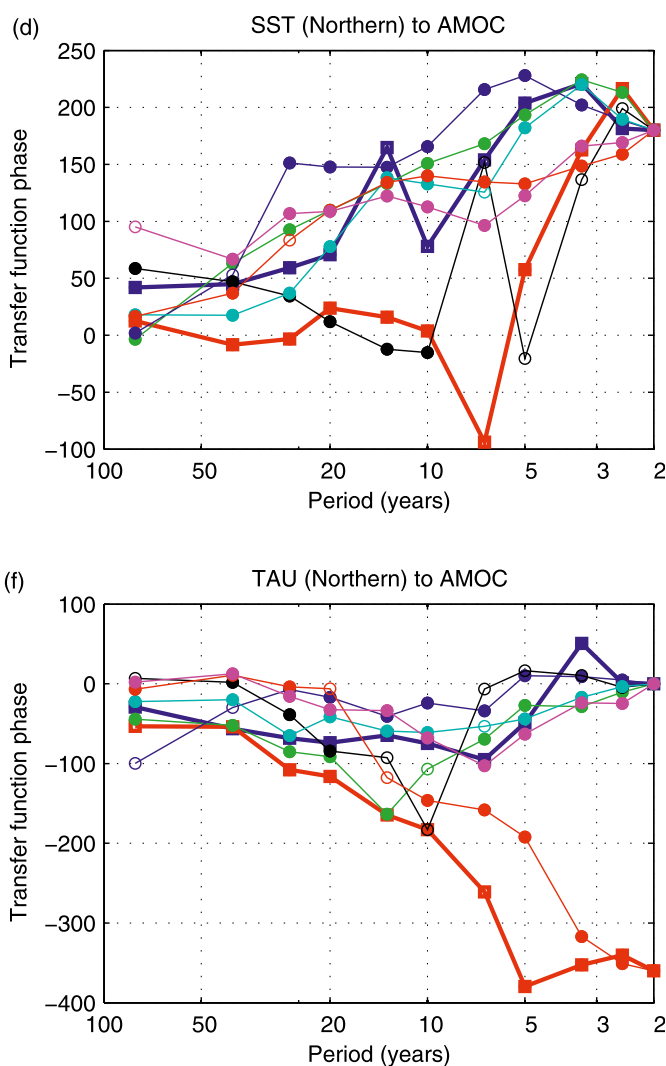

FIG. 10. Transfer function (left) magnitude and (right) phase for all models, from high-latitude (a),(b) SSS, (c), (d) SST, and (e),(f) wind stress to AMOC. Error bars are omitted for clarity; poor transfer function estimates (where a 2- $\sigma$ error exceeds the magnitude) are shown with open symbols. (Note in the final panel that $-360^{\circ}$ is the same as $\left.0^{\circ}\right)$.

perturbations in SSS and AMOC are in phase, making the direction of influence more difficult to assess. It is likely (as suggested earlier by the similarity between EOF and regression patterns) that both directions of influence are active in this model for SSS. Again, the $180^{\circ}$ phase lag at high frequencies, consistent between models, indicates that SSS and AMOC perturbations are out of phase with each other; this might result from different physics with a different sign effect or from exciting an ocean mode above its resonant frequency.

For SST, the phase (Fig. 10d) suggests that AMOC variability in the 10-30-yr band leads the corresponding SST perturbations (confirmed by a lag-correlation plot similar to Fig. 9d, not shown). However, the phase (and lag-correlation plot) indicates that wind stress perturbations at periods of 10-30 years (Fig. 10f) lead 
variability in AMOC in all models, by as much as 7 years for GFDL CM2.1. SST transfer function results should thus be interpreted with some caution regarding causality, while the wind stress results are unambiguous in this regard.

The results for the lead-lag relations between SST, SSS, and AMOC are consistent with those of Delworth et al. (1993), who found salinity in their previous version of the GFDL model to be in phase with the AMOC and temperature to lag by a few years. Griffies and Tziperman (1995) showed these results to be consistent with the excitation of a single oscillatory mode in the GFDL models. For the CCSM4 model (which does not show a significant spectral AMOC peak), the temperature also lags AMOC but, more significantly, salinity leads by a few years rather than being in phase; the difference in phase relations might thus provide some clues as to the nature of the oscillatory behavior.

Let us now consider all eight of the models in Table 1 in order to assess whether the differences in the transfer functions between GFDL CM2.1 and CCSM4 are robust. The transfer functions are plotted in Fig. 10 for SSS, SST, and TAU. The discrepancy between models in representing these processes is substantially larger than the transfer function error estimates (not shown in Fig. 10 for clarity; shown for two models in Fig. 9). Even ignoring obvious outliers, the spread in transfer function magnitude between models (left column of Fig. 10) is about a factor of 2 at very low frequencies and much larger, a factor of 10 and above, for periods of 10-30 years. There is not even an agreement on the sign of the transfer function estimate, as indicated by phase differences as large as $180^{\circ}$ (right panels of Fig. 10). For example, the phase indicates that for 10-30-yr periods, sea surface salinity perturbations lead AMOC perturbations in most models but occur roughly in phase for the two GFDL models, while AMOC perturbations lead salinity perturbations in NorESM1-M. This is potentially a consequence of both SSS influencing AMOC and AMOC influencing SSS, with the relative strength of these two relationships depending on the model and depending on frequency. Note that the significantly smaller amplitude of the transfer functions for CanESM2 results from this model predicting the region of maximum correlation between the surface fields and AMOC much farther south than the other models (see Fig. 6).

This large spread between model representations of process dynamics (using a common definition of spatial patterns) suggests the presence of very large systematic errors in describing how AMOC responds to variability in high-latitude surface forcing. Recognizing the discrepancy is not sufficient to identify specific model parameters or parameterizations responsible for the differences. In the next section, we use transfer functions to evaluate two proposed physical mechanisms that may be involved in these differences. A more thorough analysis beyond considering individual mechanisms would require breaking the pathway to AMOC from SST, SSS, or TAU into more detailed subcomponents, such as evaluating the effect of surface forcing on meridional or latitudinal density gradients, velocities at different levels, and so on. This is beyond the scope of this paper as the number of possible transfer function increases rapidly when looking at more detailed processes.

Beyond simply indicating model differences, the large scatter between models also contains some key insights on the oscillatory AMOC behavior seen in some models but not in others. Recall from Fig. 1 that both of the GFDL models and NorESM1-M had spectral peaks near 20-yr periods, and MRI-CGCM3 has a narrow peak at roughly an 8 -yr period. The three models with spectral peaks near a 20 -yr period correspond to the models with the largest AMOC response to all three surface fields (SST, SSS, and TAU) in this frequency region. Furthermore, while MRI-CGCM3 does not have an unusually large response to SSS at an 8-yr period, it has the largest response of any model to either SST or TAU at this frequency (red circles in Figs. 10c,e). This multimodel result is consistent with the differences described above in comparing CCSM4 and GFDL CM2.1, suggesting that this is a robust result across models. We conclude that a key reason for the difference in the existence or lack of AMOC oscillations (spectral peak) lies in the discrepancy in capturing how variability at high latitudes in these surface fields leads to perturbations in AMOC. These intermodel differences (and hence model errors) occur in a relatively narrow frequency range and might not be as evident without an explicit frequency domain approach.

\section{Evaluating AMOC variability mechanisms}

We next turn to exploring the physical mechanisms underlying model differences in AMOC variability, focusing again on CCSM4 and GFDL CM2.1. Several mechanisms and factors have been suggested to influence AMOC variability, and we focus on two in particular: the effect of stratification in the Labrador Sea, which is impacted by Nordic Sea overflows (Yeager and Danabasoglu 2012; Zhang et al. 2011), and the westward propagation of a subsurface (thermal) Rossby wave (Frankcombe et al. 2009; Te Raa and Dijkstra 2002).

The inclusion of a Nordic Sea overflow parameterization has been shown to reduce AMOC variability in CCSM4; Yeager and Danabasoglu (2012) showed that the overflow parameterization results in increased 

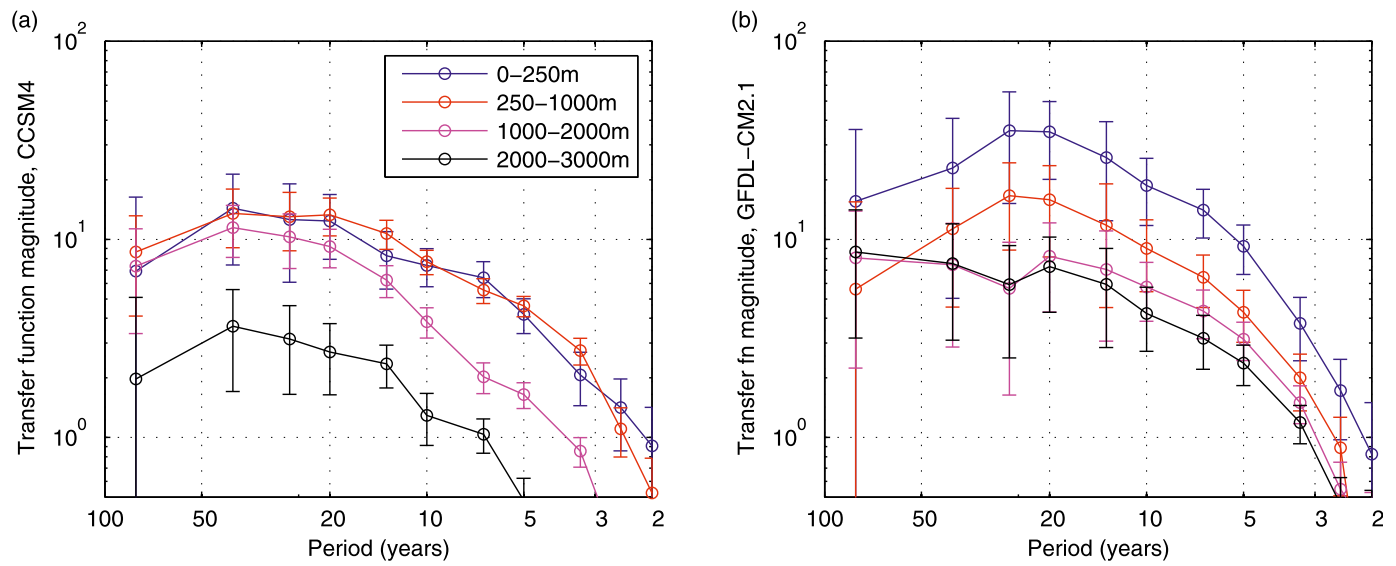

FIG. 11. Transfer function from surface wind stress over northern region to Labrador Sea temperature at depth for (a) CCSM4 and (b) GFDL CM2.1. Temperature is averaged over $50^{\circ}-60^{\circ} \mathrm{N}$ and $300^{\circ}-320^{\circ} \mathrm{E}$ and upper $250 \mathrm{~m}$ (blue), 250-1000 m (red), 1000-2000 m (magenta), and 2000-3000 m (black).

stratification in the Labrador Sea and reduces the penetration of surface variability to depth, hence leading to a weaker AMOC variability. We find a stronger AMOC variability in the GFDL CM2.1 model, and there is indeed less stratification in the Labrador Sea region in this model compared to CCSM4. In particular, in CCSM4 the potential density increases slightly below $2000 \mathrm{~m}$ as described in Yeager and Danabasoglu (2012), while this denser layer is not observed in GFDL CM2.1. The GFDL model also has higher interannual density variations both below $2000 \mathrm{~m}$ and in the upper $1000 \mathrm{~m}$ of the Labrador Sea. Between 1000 and $2000 \mathrm{~m}$ the overall density variance is similar for the two models.

To evaluate whether differences between the penetration of surface disturbances to depth are responsible for the differences in the characteristics of AMOC variability between these two models, we evaluate the transfer function between surface forcing and the temperature at increasing depth, averaged over $50^{\circ}-60^{\circ} \mathrm{N}$ and $300^{\circ}-$ $320^{\circ} \mathrm{E}$. Figure 11 displays the transfer function quantifying the ocean temperature response to wind stress forcing over the northern region in Fig. 9c. The temperature response is examined for the upper 250, 250$1000,1000-2000$, and $2000-3000 \mathrm{~m}$ (the SST response is similar to the upper 250-m response). The figure shows that in the CM2.1 model, wind stress perturbations with periods around 20 years in particular result in higher subsurface temperature variability in the upper $1000 \mathrm{~m}$ than in CCSM4. However, in the upper $2000 \mathrm{~m}$, the response to surface forcing is more strongly attenuated with depth in GFDL CM2.1 than in CCSM4, with attenuation of the variability at the dominant 20 -yr period in particular. A second striking difference is that in CCSM4, the temperature response is significantly attenuated below 2000-m depth, while this deepest layer remains excited by surface perturbations in the GFDL model. Unlike the upper $1000 \mathrm{~m}$, however, there is no preferential 20-yr period evident in the response of the sub-2000-m layer to surface forcing. This suggests that changes in Labrador Sea stratification may indeed contribute to the overall broadband increase in the GFDL AMOC spectrum seen in Fig. 1, consistent with the observation in Yeager and Danabasoglu (2012) for CCSM4. However, our frequency-resolved method shows no indication that the spectral peak in AMOC variability in GFDL CM2.1 is the result of deeper penetration of anomalies that result from surface forcing.

Note that the results in Fig. 11 are broadly similar if considering density at depth rather than temperature or for other surface forcing fields than wind forcing.

Another physical mechanism that has been proposed to explain the oscillatory AMOC behavior is the eastwest propagation of a subsurface thermal Rossby wave (Frankcombe et al. 2009; Te Raa and Dijkstra 2002). The phase of this wave influences the strength of the overturning, thus resulting in AMOC variability at a period associated with the east-west propagation time across the Atlantic. If this mechanism is indeed responsible for the observed behavior, we expect an east-west subsurface temperature difference to have a stronger influence on AMOC than a comparable temperature anomaly that is in phase across the Atlantic, particularly at the frequency associated with the peak in the AMOC spectrum.

To test this hypothesis, we construct two temperature indices by averaging over the upper-1000-m ocean depth, over $40^{\circ}-50^{\circ} \mathrm{N}$, and over eastern $\left(330^{\circ}-350^{\circ} \mathrm{E}\right)$ and western $\left(300^{\circ}-320^{\circ} \mathrm{E}\right)$ regions of the north Atlantic. Note that the regression pattern between AMOC and SST has a different sign between these two regions for both models (Fig. 5); a similar pattern holds if the regression 
(a)

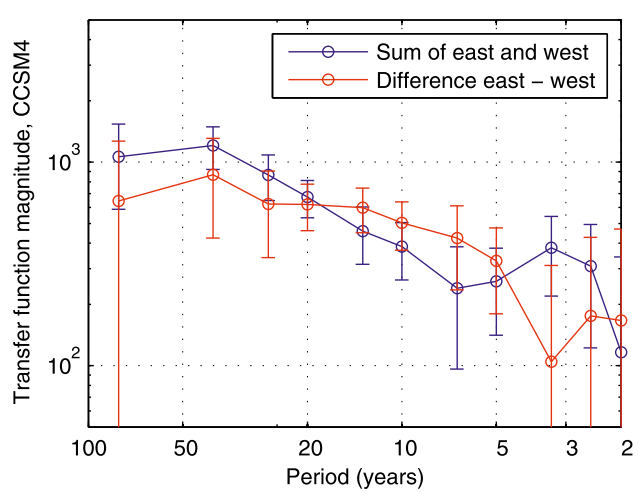

(c)

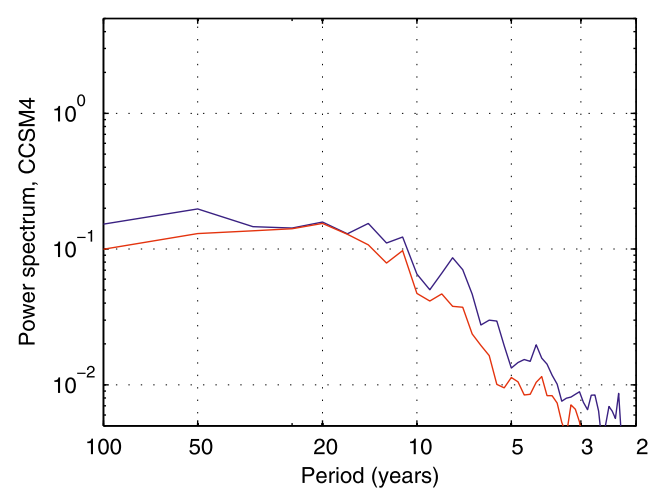

(b)

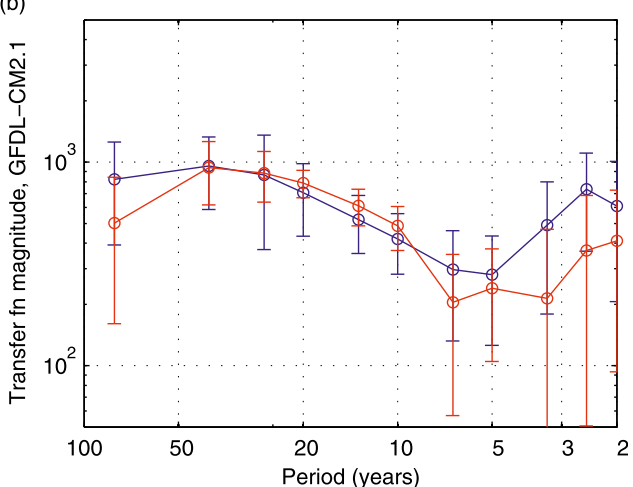

(d)

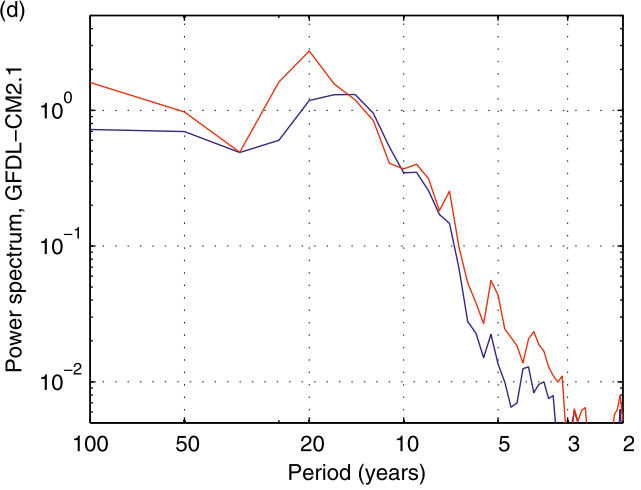

FIG. 12. Evaluation of thermal Rossby wave mechanism for exciting AMOC oscillations in (left) CCSM4 and (right) GFDL CM2.1. The temperature in the upper $1000 \mathrm{~m}$ is averaged over $40^{\circ}-50^{\circ} \mathrm{N}$ and over eastern $\left(330^{\circ}-350^{\circ} \mathrm{E}\right)$ and western $\left(300^{\circ}-320^{\circ} \mathrm{E}\right)$ regions of the North Atlantic, and (a),(b) transfer functions to AMOC are evaluated from the average over these two regions (blue) and difference (red). (c),(d) The power spectrum of these variables.

is performed for the average temperature over the upper $1000 \mathrm{~m}$. The temperature difference between these two regions is taken as indicative of the east-west subsurface temperature gradient associated with the westwardpropagating thermal Rossby wave. We compare this temperature difference with the sum of temperature averaged over these two regions.

The transfer functions between these two sum and difference indices on the one hand and the AMOC on the other are shown in Figs. 12a,b for CCSM4 and GFDL CM2.1. There are two clear conclusions from this plot: first, there is no significant difference between the models for these two transfer functions, and second, there is no significant difference in how strongly variability in either of these temperature indices results in AMOC variability. However, there is a striking difference in the power spectrum of these two temperature indices, shown in Figs. 12c,d. Not only is the overall upper-ocean temperature variability higher for the GFDL model compared with CCSM4 (evident in both the sum of east and west and the difference), but there is also a marked increase in energy in the east-west temperature difference at a 20 -yr period in the GFDL model. This suggests that there may be a connection between the thermal Rossby wave and the spectral peak of AMOC in GFDL CM2.1, as suggested by Frankcombe et al. (2009); although this Rossby wave is not necessarily a dominant excitation mechanism of AMOC variability. This is seen by the fact that the difference in temperature pattern is not more efficient at exciting AMOC than the comparable meridionally coherent temperature anomaly. This Rossby wave is itself preferentially excited at 20-yr periods in the GFDL model but not in CCSM4, although it is still not clear what leads to this model difference.

\section{Conclusions}

There is a considerable spread between different models in the nature and amplitude of interannual to decadal variability in the Atlantic meridional overturning circulation (AMOC). The model differences imply a significant uncertainty in the decadal variability of the climate system more broadly. We analyze the response of 
the AMOC to surface forcing (sea surface temperature, salinity, and wind forcing) in eight Intergovernmental Panel on Climate Change (IPCC) models. The analysis is performed in the frequency domain, using transfer functions, allowing us to concentrate on the frequency band of 10-30 years in which several models exhibit significant peaks in the power spectrum, while others show no peak at all. The existence of such spectral peaks implies a higher predictability (Griffies and Bryan 1997) and is therefore important to understand. We show that frequency domain analysis using transfer functions can be used to understand these (frequency dependent) differences.

As a first step in this analysis, we find by examining EOFs of the AMOC streamfunction that AMOC variability at a single latitude may overemphasize differences between models, since there are significant peaks in the power spectrum associated with variability of the latitude where the peak overturning exists. Nonetheless, significant differences between models remain even when considering the overall amplitude of the overturning circulation (which we find to be reflected by the first EOF of the streamfunction) rather than that at a given latitude.

Previous studies of AMOC oscillations found that the SSS is nearly in phase with AMOC oscillations, while the SST lags significantly, and used this to explain the oscillatory behavior (Delworth et al. 1993; Griffies and Tziperman 1995). However, we find here that these lead-lag relations exist regardless of whether the model AMOC has a significant oscillatory signal. This highlights the fact that our understanding of AMOC oscillations is still lacking.

We show that model differences in the relationship between AMOC and surface salinity, surface temperature, and wind stress magnitude are consistent with differences in the power spectra of AMOC variability. Specifically, we find that models with a larger sensitivity of the AMOC to surface fields (i.e., larger transfer function magnitude) at decadal periods are also characterized by clear oscillatory AMOC variability and corresponding spectral peaks at these periods. Models where the transfer function amplitude is smaller show no AMOC spectral peaks. This suggests that model representation of the connection between surface forcing and AMOC is a key component in understanding the different nature of AMOC oscillatory behavior across models.

While intriguing, this insight cannot lead directly to specific model improvement and to resolving the question of whether AMOC variability should be characterized by spectral peaks because it is not obvious which model parameters or parameterizations are responsible for the strength of the model AMOC response to surface forcing fields. This can hopefully be resolved by future work examining transfer functions involving the response of interior density gradients to surface forcing and the effects of such density gradient on AMOC variability. We consider here two specific mechanisms that have been proposed to explain AMOC variability. First, increased stratification in the Labrador Sea has been shown to decrease AMOC variance in CCSM4 by reducing the penetration of surface perturbations to depth (Yeager and Danabasoglu 2012). We find that there is indeed a stronger penetration of surface forcing to below $2000 \mathrm{~m}$ in the GFDL model, which also has a stronger AMOC variability. However, because this penetrating signal does not peak at 20 -yr periods, it is not clear that this mechanism is responsible for the spectral peak at 20 years of the AMOC. Second, subsurface thermal Rossby waves have been proposed as a mechanism for inducing a 20-yr period in AMOC variability. We find that an east-west subsurface temperature gradient related to such propagating waves is not more effective at exciting AMOC variability than a comparable temperature anomaly not related to such waves, nor more effective at exciting AMOC in GFDL CM2.1 than in CCSM4. However, the power spectrum of the east-west subsurface temperature gradient has a peak at a 20 -yr period, indicating that this mechanism may indeed play a role.

It is important to emphasize that these process-based analyses again rely on the ability to separate out effects occurring at different frequencies; we hope that the transfer function tool used here may be more broadly useful in further clarifying the mechanisms underlying the spectral characteristics of AMOC variability in models.

Acknowledgments. This work was supported by Grant DE-SC0004984 from the DOE Climate and Environmental Sciences Division, Office of Biological and Environmental Research (DM and ET). LZ was supported by the U.K. Natural Environment Research Council, Grant NE/J00586X/1. Eli Tziperman thanks the Weizmann Institute for its hospitality during parts of this work. We acknowledge the World Climate Research Programme's Working Group on Coupled Modelling, which is responsible for CMIP, and we thank the climate modeling groups (listed in Table 1) for producing and making available their model output. For CMIP the U.S. Department of Energy's Program for Climate Model Diagnosis and Intercomparison provides coordinating support and led development of software infrastructure in partnership with the Global Organization for Earth System Science Portals.

\section{REFERENCES}

Alexander, J., and A. H. Monahan, 2009: Nonnormal perturbation growth of pure thermohaline circulation using a 2D zonally averaged model. J. Phys. Oceanogr., 39, 369-386. 
Astrom, K. J., and R. M. Murray, 2008: Feedback Systems: An Introduction for Scientists and Engineers. Princeton University Press, $424 \mathrm{pp}$

Bingham, R., C. W. Hughes, V. Roussenov, and R. G. Williams, 2007: Meridional coherence of the North Atlantic meridional overturning circulation. Geophys. Res. Lett., 34, L23606, doi:10.1029/2007GL031731.

Bjerknes, J., 1964: Atlantic air-sea interaction. Advances in Geophysics, Vol. 10, Academic Press, 1-82.

Booth, B. B. B., N. J. Dunstone, P. R. Halloran, T. Andrews, and N. Bellouin, 2012: Aerosols implicated as a prime driver of twentieth-century North Atlantic climate variability. Nature, 484, 228-232.

Bryan, F. O., G. Danabasoglu, N. Nakashiki, Y. Yoshida, D. H. Kim, J. Tsutsui, and S. C. Doney, 2006: Response of the North Atlantic thermohaline circulation and ventilation to increasing carbon dioxide in CCSM3. J. Climate, 19, 2382-2397.

Buckley, M. W., D. Ferreira, J. Campin, J. Marshall, and R. Tulloch, 2012: On the relationship between decadal buoyancy anomalies and variability of the Atlantic meridional overturning circulation. J. Climate, 25, 8009-8030.

Cessi, P., 1994: A simple box model of stochastically forced thermohaline flow. J. Phys. Oceanogr., 24, 1911-1920.

Chen, F., and M. Ghil, 1995: Interdecadal variability of the thermohaline circulation and high-latitude surface fluxes. J. Phys. Oceanogr., 25, 2547-2568.

Cheng, W., J. C. H. Chiang, and D. Zhang, 2013: Atlantic meridional overturning circulation (AMOC) in CMIP5 models: RCP and historical simulations. J. Climate, 26, 7187-7197.

Cunningham, S. A., and Coauthors, 2007: Temporal variability of the Atlantic meridional overturning circulation at 26.5 degrees N. Science, 317, 935-938.

Delworth, T., and R. J. Greatbatch, 2000: Multidecadal thermohaline circulation variability driven by atmospheric surface flux forcing. J. Climate, 13, 1481-1495.

_ , S. Manabe, and R. J. Stouffer, 1993: Interdecadal variations of the thermohaline circulation in a coupled ocean-atmosphere model. J. Climate, 6, 1993-2011.

Deser, C., and M. L. Blackmon, 1993: Surface climate variations over the North Atlantic Ocean during winter: 1900-1989. J. Climate, 6, 1743-1753.

Doblas-Reyes, F., M. A. Balmaseda, A. Weisheimer, and T. N. Palmer, 2011: Decadal climate prediction with the European Centre for Medium-Range Weather Forecasts coupled forecast system: Impact of ocean observations. J. Geophys. Res., 116, D19111, doi:10.1029/2010JD015394.

Dong, B. W., and R. T. Sutton, 2001: The dominant mechanism of variability in Atlantic Ocean heat transport in a coupled ocean-atmosphere GCM. Geophys. Res. Lett., 28, 2445-2448.

Elipot, S., C. Hughes, S. Olhede, and J. Toole, 2013: Coherence of western boundary pressure at the RAPID WAVE array: Boundary wave adjustments or deep western boundary current advection? J. Phys. Oceanogr., 43, 744-765.

Enfield, D. B., A. M. Mestas-Nuñez, and P. J. Trimble, 2001: The Atlantic multidecadal oscillation and its relation to rainfall and river flows in the continental U.S. Geophys. Res. Lett., 28, 2077-2080.

Frankcombe, L. M., H. A. Dijkstra, and A. V. Heydt, 2009: Coherent multidecadal variability in North Atlantic sea level. Geophys. Res. Lett., 36, L15604, doi:10.1029/2009GL039455.

Frankignoul, C., and K. Hasselmann, 1977: Stochastic climate models. Part II: Application to sea surface temperature variability and thermocline variability. Tellus, 29, 284-305.
Froelicher, T. L., F. Joos, G. K. Plattner, M. Steinacher, and S. C. Doney, 2009: Natural variability and anthropogenic trends in oceanic oxygen in a coupled carbon cycle-climate model ensemble. Global Biogeochem. Cycles, 23, GB1003, doi:10.1029/ 2008 GB003316.

Greatbatch, R. J., and S. Zhang, 1995: An interdecadal oscillation in an idealized ocean basin forced by constant heat flux. J. Climate, 8, 81-91.

Gregory, J. M., and Coauthors, 2005: A model intercomparison of changes in the Atlantic thermohaline circulation in response to increasing atmospheric $\mathrm{CO}_{2}$ concentration. Geophys. Res. Lett., 32, L12703, doi:10.1029/2005GL023209.

Griffies, S. M., and E. Tziperman, 1995: A linear thermohaline oscillator driven by stochastic atmospheric forcing. J. Climate, 8, 2440-2453.

, and K. Bryan, 1997: Predictability of North Atlantic multidecadal climate variability. Science, 275, 181-184.

Hawkins, E., and R. Sutton, 2009: The potential to narrow uncertainty in regional climate predictions. Bull. Amer. Meteor. Soc., 90, 1095-1107.

Kanzow, T., and Coauthors, 2008: A prototype system for observing the Atlantic meridional overturning circulationScientific basis, measurement and risk mitigation strategies, and first results. J. Oper. Oceanogr., 1, 19-28.

Keenlyside, N. S., M. Latif, J. Jungclaus, L. Kornblueh, and E. Roeckner, 2008: Advancing decadal-scale climate prediction in the North Atlantic sector. Nature, 453, 84-88.

Kushnir, Y., 1994: Interdecadal variations in North Atlantic sea surface temperature and associated atmospheric conditions. J. Climate, 7, 141-157.

Lohmann, G., and J. Schneider, 1999: Dynamics and predictability of Stommel's box model. A phase-space perspective with implications for decadal climate variability. Tellus, 51A, 326-336.

Lozier, M. S., V. Roussenov, S. Mark, C. Reed, and R. Williams, 2010: Opposing decadal changes for the North Atlantic meridional overturning circulation. Nat. Geosci., 3, 728-734.

MacMynowski, D. G., and E. Tziperman, 2010: Testing and improving ENSO models by process using transfer functions. Geophys. Res. Lett., 37, L19701, doi:10.1029/2010GL044050.

Mahajan, S., R. Zhang, and T. L. Delworth, 2011: Impact of the Atlantic meridional overturning circulation (AMOC) on Arctic surface air temperature and sea ice variability. J. Climate, 24, 6573-6581.

Mann, M. E., and J. Park, 1994: Global-scale modes of surfacetemperature variability on interannual to century timescales. J. Geophys. Res., 99 (D12), 25 819-25833.

Marshall, J., H. Johnson, and J. Goodman, 2001: A study of the interaction of the North Atlantic Oscillation with ocean circulation. J. Climate, 14, 1399-1421.

McCarthy, G. D., and Coauthors, 2012: Observed interannual variability of the Atlantic meridional overturning circulation at $26.5^{\circ}$ N. Geophys. Res. Lett., 39, L19609, doi:10.1029/ 2012GL052933.

Palmer, T. N., 2001: A nonlinear dynamical perspective on model error: A proposal for non-local stochastic-dynamic parametrization in weather and climate prediction models. Quart. J. Roy. Meteor. Soc., 127, 279-304.

Penland, C., and P. D. Sardeshmukh, 1995: The optimal-growth of tropical sea surface temperature anomalies. J. Climate, 8, 1999-2024

Smith, D. M., S. Cusack, A. W. Colman, C. K. Folland, G. R. Harris, and J. M. Murphy, 2007: Improved surface temperature 
prediction for the coming decade from a global climate model. Science, 317, 796-799.

Solomon, S., D. Qin, M. Manning, Z. Chen, M. Marquis, K. Averyt, M. Tignor, and H. L. Miller Jr., Eds., 2007: Climate Change 2007: The Physical Science Basis. Cambridge University Press, 996 pp.

Sutton, R. T., and M. R. Allen, 1997: Decadal predictability of North Atlantic sea surface temperature and climate. Nature, 388, $563-567$.

Swanson, D. C., 2000: Signal Processing for Intelligent Sensor Systems. CRC Press, 632 pp.

Te Raa, L. A., and H. A. Dijkstra, 2002: Instability of the thermohaline ocean circulation on interdecadal timescales. J. Phys. Oceanogr., 32, 138-160.

Timmermann, A., M. Latif, R. Voss, and A. Grotzner, 1998: Northern Hemispheric interdecadal variability: A coupled air-sea mode. J. Climate, 11, 1906-1931.

Ting, M. F., Y. Kushnir, R. Seager, and C. H. Li, 2009: Forced and internal twentieth-century SST trends in the North Atlantic. J. Climate, 22, 1469-1481.

Tulloch, R., and J. Marshall, 2012: Exploring mechanisms of variability and predictability of Atlantic meridional overturning circulation in two coupled climate models. J. Climate, 25, 4067-4080.

Tziperman, E., and P. J. Ioannou, 2002: Transient growth and optimal excitation of thermohaline variability. J. Phys. Oceanogr., 32, 3427-3435.

Weaver, A. J., E. S. Sarachik, and J. Marotze, 1991: Fresh-water flux forcing of decadal and interdecadal oceanic variability. Nature, 353, 836-838.
, J. Marotzke, P. F. Cummins, and E. S. Sarachik, 1993: Stability and variability of the thermohaline circulation. J. Phys. Oceanogr., 23, 39-60.

Winton, M., and E. S. Sarachik, 1993: Thermohaline oscillation induced by strong steady salinity forcing of ocean general circulation models. J. Phys. Oceanogr., 23, 1389-1410.

Xiuhua, Z., and J. Jungclaus, 2008: Interdecadal variability of the meridional overturning circulation as an ocean internal mode. Climate Dyn., 31, 731-741.

Yeager, S., and G. Danabasoglu, 2012: Sensitivity of Atlantic meridional overturning circulation variability to parameterized Nordic Sea overflows in CCSM4. J. Climate, 25, 20772103.

Zanna, L., and E. Tziperman, 2005: Nonnormal amplification of the thermohaline circulation. J. Phys. Oceanogr., 35, 1593-1605.

—, P. Heimbach, A. M. Moore, and E. Tziperman, 2011: Optimal excitation of interannual Atlantic meridional overturning circulation variability. J. Climate, 24, 413-427.

,,--- , and -2012 : Upper ocean singular vectors of the North Atlantic climate with implications for linear predictability and variability. Quart. J. Roy. Meteor. Soc., 138, 500-513.

Zhang, R., 2008: Coherent surface-subsurface fingerprint of the Atlantic meridional overturning circulation. Geophys. Res. Lett., 35, L20705, doi:10.1029/2008GL035463.

—, T. L. Delworth, A. Rosati, W. G. Anderson, K. W. Dixon, H.-C. Lee, and F. Zeng, 2011: Sensitivity of the North Atlantic Ocean circulation to an abrupt change in Nordic Sea overflow in a high resolution global coupled climate model. J. Geophys. Res., 116, C12024, doi:10.1029/2011JC007240. 